\title{
Biochar and Compost Amendments Enhance Copper Immobilisation and Support Plant Growth in Contaminated Soils.
}

Jones, Sarah ${ }^{\text {a; }}$ Bardos, R. Paul ${ }^{\text {a }}$; Kidd, Petra S. ${ }^{\text {; }}$; Mench Michel ${ }^{c, d}$; de Leij, Frans ${ }^{e}$; Hutchings, Tony ${ }^{\mathrm{e}}$; Cundy, Andrew ${ }^{\dagger}$; Joyce, Chris ${ }^{\dagger}$; Soja, Gerhard ${ }^{g}$; Friesl-Hanl, Wolfgang ${ }^{g}$; Herzig, Rolf ${ }^{\mathrm{h}}$; Menger, Pierre ${ }^{i}$

${ }^{a}$ r3 environmental technology UK Itd, H9 TOB1, University of Reading Whiteknights Campus, Reading, UK. sarah@r3environmental.co.uk; paul@r3environmental.co.uk.

${ }^{b}$ Instituto de Investigaciones Agrobiológicas de Galicia (IIAG), Consejo Superior de Investigaciones Científicas (CSIC), Santiago de Compostela 15706, Spain.

pkidd@iiag.csic.es

'UMR BIOGECO INRA 1202, Ecologie des Communautés, Université de Bordeaux, Bât. B2, allée Geoffroy St-Hilaire, CS50023, F-33615 Pessac cedex, France.

mench@bordeaux.inra.fr

'INRA, UMR BIOGECO INRA 1202, 69 Route d'Arcachon, 33610 Cestas, France.

${ }^{e}$ C-Cure Solutions Ltd. Forest Research, Wrecclesham, Farnham, Surrey, UK.

tony@ccuresolutions.com; frans@ccuresolutions.com.

${ }^{f}$ Environment and Technology, University of Brighton, Lewes Road, Brighton, BN2 4GJ, UK. A.cundy@brighton.ac.uk

${ }^{g}$ AIT Austrian Institute of Technology $\mathrm{GmbH}$, Konrad Lorenz-Str. 24, 3430 Tulln, Austria.

Wolfgang.friesl@ait.ac.at; Gerhard.soja@ait.ac.at

hPhytotech Foundation \& AGB, Quartiergasse 12 CH3013 Berne, Switzerland.

rolf.herzig.agb@bleuwin.ch

'Tecnalia Research \& Innovation, Parque Tecnológico de Bizkaia, E-48160 Derio - Bizkaia Spain._pierre.menger@tecnalia.com

Corresponding author: Paul Bardos paul@r3environmental.co.uk Tel: +44(0)118 378 8164; Mob: +44(0)7961200 118; Fax: +44(0)118329 0476. 


\begin{abstract}
Contamination of soil with trace elements, such as $\mathrm{Cu}$, is an important risk management issue. A pot experiment was conducted to determine the effects of three biochars and compost on plant growth and the immobilisation of $\mathrm{Cu}$ in a contaminated soil from a site formerly used for wood preservation. To assess $\mathrm{Cu}$ mobility, amended soils were analysed using leaching tests pre- and post-incubation, and post-growth. Amended and unamended soils were planted with sunflower, and the resulting plant material was assessed for yield and $\mathrm{Cu}$ concentration. All amendments significantly reduced leachable Cu compared to the unamended soil, however, the greatest reductions in leachable $\mathrm{Cu}$ were associated with the higher biochar application rate. The greatest improvements in plant yields were obtained with the higher application rate of biochar in combination with compost. The results suggest joint biochar and compost amendment reduces Cu mobility and can support biomass production on $\mathrm{Cu}$-contaminated soils.
\end{abstract}

\title{
Keywords
}

Organic amendments; sunflower; Leaching tests; Plant trials; Trace elements; In situ stabilisation

\section{Highlights}

- Cu-contaminated soil was amended with three biochars singly and with compost

- Leaching tests and plant trials determined Cu mobility and plant growth

- All amendments reduced Cu mobility and facilitated plant growth

- Biochar and compost amendments could facilitate plant growth on Cucontaminated soil 


\section{Introduction}

Trace element (TE) contamination of soils is a challenging risk management issue. TEs do not degrade over time and are therefore persistent in the environment (Megharaj et al., 2011), and conventional methods for their remediation (e.g. dig and dump) are often costly (Bolan et al., 2014) and non-sustainable. An interesting low input approach to in situ remediation of TE contaminated soils may be the use of amendments such as biochar and compost.

Biochar is the carbon-rich end product of biomass pyrolysis. It has diverse potential environmental applications. Amongst other uses, biochar may be used in carbon sequestration, bioenergy production and agricultural waste recycling (Ahmad et al., 2014). Biochar may also be an immobilisation agent for TE in contaminated soil (Venegas et al., 2015; Houben et al., 2013; Khan et al., 2013; Beesley \& Marmiroli, 2011; Park et al., 2011; Sizmur et al., 2011). Biochar's ability to sorb contaminants has been attributed to an increase in oxygen-containing surface functional groups (carboxyl, hydroxyl and phenolic) with biochar addition to soil (Tong et al., 2011; Uchimiya et al., 2011). Biochar is also highly durable (Gurwick et al., 2013) which could result to a long term immobilisation effect. Whilst biochars have been shown to reduce the bioavailability of TE in soils, further study of this process is required in a range of contaminated soils in order to fully understand both its potential and its limitations.

Compost amendment has also been used in the remediation of contaminated soil. Compost addition can reduce the exchangeable fraction in soil for a number of TE, due to increased cation exchange capacity (CEC) and the strong affinity of metals for organic complexation sites (Bes and Mench, 2008; Fleming et al., 2013). Alvarenga et al. (2009) showed that composts derived from green waste and municipal solid waste reduced mobile concentrations of copper $(\mathrm{Cu})$, lead $(\mathrm{Pb})$ and zinc $(\mathrm{Zn})$ as a consequence of altered soil chemical characteristics, including increased $\mathrm{pH}$ and organic matter $(\mathrm{OM})$ content.

Biochar and compost incorporation into soil for remediation purposes also provides soil fertility improvements (including nutrient provision, enhanced CEC, improved soil structure and water retention, and $\mathrm{pH}$ control). These wider benefits may also be very useful for brownfield sites, which commonly have poor soil quality (Mallik \& Karim, 2008; Nixon et al., 2001). Additionally, higher plant yields obtained with organic amendment addition may support increased biomass production on brownfields, and therefore enhanced phytoremediation (Beesley et al., 2011).

In this study, we investigated the effects of three biochars and compost on plant growth and Cu mobility in a contaminated soil from a former wood preservation site. Leaching tests were performed on amended soils to determine Cu mobility, and plant (pot) trials were undertaken to assess impacts on plant growth and plant metal concentrations. Sunflower was selected as the trial plant as it has high adaptability and aesthetic appeal, and is widely used as a biofuel substrate (Zhao et al., 2014; Mench et al., 2010; Amon et al., 2007; Gerçel, 2002). The IBL04 sunflower mother clone was chosen for its relatively high metal tolerance (Herzig et al., 2014; 
Nehnevajova et al., 2007, 2009) and has previously been cultivated in the field in amended soils at the Gironde site (Kolbas et al., 2014)

\section{Materials and Methods}

\subsection{Study Site and Soil Sampling}

Cu contaminated soil was obtained from a former wood preservation site in the Gironde County Saint Médard d'Eyrans, France (N 44 ${ }^{0} \quad 43.353$, W $000^{\circ} 30.938$ ) (Bes et al., 2010). Soil was sampled randomly and collected in February 2014 with an unpainted stainless steel spade from the P7 sub-site $(0-25 \mathrm{~cm}$ depth) which has previously been investigated by Bes \& Mench (2008), Mench \& Bes (2009), and Bes et al. (2010). Soil material (5 subsamples totalling $100 \mathrm{~kg}$ ) was manually homogenised and sieved to $4 \mathrm{~mm}$. The P7 soil (WRB classification: Eutric gleysol; $\mathrm{pH}_{\text {water }} 7$; LOI $3 \%$ ) is largely classified as a sandy loam. At the P7 sub-site, wood was dipped in creosote and Cu sulphate as preservative treatments. The P7 soil consequently has high levels of $\mathrm{Cu}$ and polycyclic aromatic hydrocarbon (PAH) contamination (see supplementary materials for detailed soil analysis of: PAHs, trace elements, hydrocarbons and BTEX http://doi.pangaea.de/10.1594/PANGAEA.846932).

\section{$2.2 \quad$ Amendments}

Three biochars were tested: BC1, BC2 and BC3. BC1 ( $\mathrm{pH}_{\text {water }} 10$; LOI 49\%) was a specialised biochar agent, $C$-Cure Metal, developed and patented for the remediation of metal contaminated substrates (C-Cure Solutions ${ }^{\mathrm{TM}}{ }^{\mathrm{L}} \mathrm{Ltd}$, Farnham, UK) ${ }^{1}$ (patent number: WO2009016381 A2). BC2 (pH water 10; LOI 42\%) and BC3 $\left(\mathrm{pH}_{\text {water }} 10\right.$; LOI $\left.40 \%\right)$ were produced by the AIT (Austrian Institute of Technology $\mathrm{GmbH}$ ) in co-operation with Sonnenerde $\mathrm{GmbH}$ using chopped poplar wood previously harvested from the $\mathrm{P} 7$ sub-site. $\mathrm{BC} 2$ and $\mathrm{BC} 3$ were produced via pyrolysis at $525^{\circ} \mathrm{C}$ in a Pyreg reactor (Pyreg $\mathrm{GmbH}$, Dörth, Germany) with a residence time of approximately 15-20 minutes. BC2 was used unaltered. BC3 was mixed with $20 \% \mathrm{Fe}_{2} \mathrm{O}_{3}$ purchased from VWR (VWR International $\mathrm{GmbH}$, Darmstadt, Germany). $\mathrm{Fe}_{2} \mathrm{O}_{3}$ was trialled in an attempt to improve the number of sorption sites. Iron oxides have known sorption capabilities and have been applied as intended "sinks" for certain TE (Komárek et al., 2013; Cundy et al., 2008; Cornell \& Schwertmann, 2003). Compost ( $\mathrm{pH}_{\text {water }} 8$; LOI 18\%) made from green waste and sandy soils/sand was purchased in France and was stored at the Gironde site for one year under tarpaulin. Soil and amendments were transported to IIAG-CSIC ${ }^{2}$, Spain, where the leaching and plant trials were carried out.

\subsection{Experimental Design}

Each of the biochars was trialled as a single amendment at rates of $1 \%$ and $3 \% \mathrm{w} / \mathrm{w}$. Green waste compost $(\mathrm{C})$ was also trialled as a single amendment at application

\footnotetext{
1 www.ccuresolutions.com

${ }^{2}$ www.iiag.csic.es
} 
rates of $1 \%$ and $2 \% \mathrm{w} / \mathrm{w}$. Additionally, each of the three biochars was trialled in combination with compost, at the aforementioned application rates. Soils were amended with a total of 20 amendments alongside unamended soil (see Table 1 below).

Table 1: Sample ID showing amendments and rates

\begin{tabular}{|l|l|l|}
\hline Unamended & Compost $(1 \%)$ & $\mathrm{BC} 3(3 \%)+\mathrm{C}(1 \%)$ \\
\hline $\mathrm{BC} 1(1 \%)$ & Compost $(2 \%)$ & $\mathrm{BC} 1(1 \%)+\mathrm{C}(2 \%)$ \\
\hline $\mathrm{BC} 2(1 \%)$ & $\mathrm{BC} 1(1 \%)+\mathrm{C}(1 \%)$ & $\mathrm{BC} 2(1 \%)+\mathrm{C}(2 \%)$ \\
\hline $\mathrm{BC} 3(1 \%)$ & $\mathrm{BC} 2(1 \%)+\mathrm{C}(1 \%)$ & $\mathrm{BC} 3(1 \%)+\mathrm{C}(2 \%)$ \\
\hline $\mathrm{BC} 1(3 \%)$ & $\mathrm{BC} 3(1 \%)+\mathrm{C}(1 \%)$ & $\mathrm{BC} 1(3 \%)+\mathrm{C}(2 \%)$ \\
\hline $\mathrm{BC} 2(3 \%)$ & $\mathrm{BC} 1(3 \%)+\mathrm{C}(1 \%)$ & $\mathrm{BC} 2(3 \%)+\mathrm{C}(2 \%)$ \\
\hline $\mathrm{BC} 3(3 \%)$ & $\mathrm{BC} 2(3 \%)+\mathrm{C}(1 \%)$ & $\mathrm{BC} 3(3 \%)+\mathrm{C}(2 \%)$ \\
\hline
\end{tabular}

Prior to soil amendment, all biochars were air-dried for three days then ground to $<2 \mathrm{~mm}$. Compost was sieved to $<2 \mathrm{~mm}$ before addition and application rates were amended to allow for moisture content. For incubation trials (see below), $150 \mathrm{~g}$ aliquots of soil were amended (20 amendments, plus unamended). For plant trials, soil was sieved to $4 \mathrm{~mm}$ and bulk amended in batches of $3 \mathrm{~kg}$ (20 amendments, plus unamended). To determine the effect of the soil amendments on Cu mobility and plant growth, leaching tests and plant trials were carried out. $\mathrm{pH}$ and Dissolved Organic Carbon (DOC) were measured in parallel to leaching tests.

\section{$2.4 \quad$ Leaching Tests}

Leaching tests (adapted from Houba et al., 2000) were carried out to determine the effect of amendment application on Cu mobility in soil. Leaching tests were carried out at three "time points": "pre-incubation", "post-incubation" and "post-growth". "Preincubation" leaching tests were carried out 24 hours after amendment by removing aliquots $(2.5 \mathrm{~g})$ of amended and unamended soil to $50 \mathrm{ml}$ centrifuge tubes (4 replicate tubes per amendment) and mixing with $25 \mathrm{ml}$ of $0.01 \mathrm{M} \mathrm{CaCl}_{2}$. Samples were then placed on a shaker for 24 hours prior to centrifugation at $3752 \mathrm{~g}$ for ten minutes (J2MI, Beckman Coulter, Inc., Brea, CA, USA). Samples were extracted for 24 hours as biochar producers C-CURE have found (based on experience over several years) that whilst a 2 hour extraction gives an indication of immediate leachable $\mathrm{Cu}$ (i.e. equivalent to exchangeable) it doesn't give a good indication of releasable metals. A much better assessment of how likely metals are to be released in the longer term is given with a 24 hour extraction. In this sense, the $24 \mathrm{~h}$ test gives a very conservative assessment of exchangeable/leachable metal levels, but a realistic test of metal stability.

Following shaking, samples were filtered (8-12 $\mu \mathrm{m}$ pore; F2040 - CHMLAB Group, Barcelona, Spain) and analysed for concentration of $\mathrm{Cu}$ and other metals using ICPOES (Varian Vista-Pro, Varian Inc., Palo Alto, CA).

From each $150 \mathrm{~g}$ amended soil sample (see section 2.3), an $80 \mathrm{~g}$ sub-sample was removed, moistened with $20 \mathrm{ml}$ of water and then stored at $25^{\circ} \mathrm{C}$ in the dark for two weeks. Throughout the two week incubation, a repeated wet/dry cycle (two days wetting, followed by two days drying) was implemented to replicate conditions that may occur in the environment. Leaching tests as outlined above were repeated 
following this incubation stage ("post-incubation", 4 replicates). Soils collected after plant growth ("post-growth", 5 replicates) were also tested. Post-growth soils were sieved to and analysed at both $<4 \mathrm{~mm}$ and $<2 \mathrm{~mm}$.

\section{$2.5 \quad \mathrm{pH}$}

To determine $\mathrm{pH}$, four replicate samples $(10 \mathrm{~g})$ of each amended soil were weighed into $50 \mathrm{ml}$ centrifuge tubes. To each tube, $25 \mathrm{ml}$ of Milli-Q water was added and $\mathrm{pH}$ measured using a Metrohm $632 \mathrm{pH}$ meter (Metrohm AG, Herisau, Switzerland).

\subsection{DOC}

DOC was determined in the same 1:2.5 (w/v) soil: $\mathrm{H}_{2} \mathrm{O}$ extracts after 2 hours of shaking (adapted from Jones and Willett (2006)). Samples were centrifuged at $3752 \mathrm{~g}$ for ten minutes (J2-MI, Beckman Coulter, Inc., Brea, CA, USA) before paper filtration (8-12 $\mu \mathrm{m}$; F2040 - CHMLAB Group, Barcelona, Spain). Centrifugation and paper filtering steps were repeated due to the turbidity of samples. Following this, samples were membrane filtered at $0.22 \mu \mathrm{m}$, then acidified with one drop of reagent grade $(70 \%)$ nitric acid. After 24 hours, the supernatant of each sample was removed to a clean glass vial before analysis using a Vario TOC Cube (Elementar Analysensysteme $\mathrm{GmbH}$, Hanau, Germany). This method was repeated with soil samples post-incubation (4 replicates) and post-growth (5 replicates).

\subsection{Plant Trials}

Plant trials were conducted in June-July 2014 using the same series of amendments to determine the effect of biochar and compost addition on biomass yield and plant $\mathrm{Cu}$ concentrations. For each amendment type, five replicate pots were prepared with $750 \mathrm{~g}$ of soil. To each pot, two Helianthus annuus L. (sunflower) seeds (IBL04 mother clone, Phytotech, Bern, Switzerland) were added. Plants were watered from below, with water being placed in the saucer underneath pots for uptake. Saucers were kept wet. After germination, seedlings were thinned to one plant per pot. Plants were kept in a greenhouse with natural illumination and a maximum air temperature of 26 ${ }^{\circ} \mathrm{C}$. After seven weeks, plants were harvested, washed and separated into roots, stems and leaves. Dry biomass was recorded.

\subsection{Analysis of Plant Material}

Dried plant material was split into above ground (shoot) and below ground (root) parts and ground manually. Samples of material $(0.3-0.8 \mathrm{~g})$ were then weighed into glass test tubes. To this, $2 \mathrm{ml}$ of nitric acid (analytic reagent grade, $70 \%$ ) was added and left overnight. Hydrochloric acid $(1 \mathrm{ml}, 37 \%)$ was then added to each tube. Samples were digested at $120^{\circ} \mathrm{C}$ for 9 hours. Samples were transferred to $10 \mathrm{ml}$ volumetric flasks and made up to the mark with deionised water. Samples were then analysed via ICP-OES (Varian Vista-Pro, Varian Inc., Palo Alto, CA) for the following elements: $\mathrm{Cu}, \mathrm{Ca}, \mathrm{Fe}, \mathrm{K}, \mathrm{Mg}, \mathrm{Mn}, \mathrm{P}$, and $\mathrm{Zn}$. Blanks and reference material (hay powder No. 129, Community Bureau of References, EU) were also included in each digestion batch to subtract elements from reagents and to check for element recovery. Element recovery was $>90 \%$ of certified values. 


\subsection{Statistical Analysis}

Statistical analysis was performed using Minitab 17 (Minitab, State College, PA, USA). All datasets were assessed using Anderson-Darling tests. All datasets showed non-normal distributions, which were largely not transformable to represent normal distributions. Therefore, non-parametric statistical analyses were used. Kruskal-Wallis tests were used to determine if there were differences between the soil amendments for the variables measured. Differences between amendments preand post-incubation, pre- and post-growth and between $2 \mathrm{~mm}$ and $4 \mathrm{~mm}$ post-growth soil were established using Mann-Whitney $U$ tests. Correlations between different variables were established using Rank Spearman correlation. For all tests, a confidence level of $95 \%$ was used. Outliers were removed from the post-growth leaching test datasets. For the " $2 \mathrm{~mm}$ " dataset, one outlier was removed from the $\mathrm{C}$ $(1 \%)$ treatment and one from the BC2 $(3 \%)+C(1 \%)$ treatment. For the " $4 \mathrm{~mm}$ " dataset one outlier was removed from the BC2 (3\%) treatment and one from the BC2 $(1 \%)+C(2 \%)$ treatment. Outliers were determined using the Grubbs outlier test.

\section{Results}

\subsection{Leaching Tests}

The results of pre-incubation leaching tests showed a significant reduction in leachable $\mathrm{Cu}$ across all amendments relative to the unamended soil (see Figure 1). Kruskal-Wallis testing found a significant difference between amendments $(p<0.01)$. For biochar only amendments, leachable $\mathrm{Cu}$ was reduced in the order: $\mathrm{BC} 1>\mathrm{BC} 2>\mathrm{BC} 3$ for both the lower and higher rates of application. This trend was repeated in the combined amendments at $1 \%$ compost addition. Combined compost and biochar amendments improved the performance of the $1 \%$ biochar application rate. The greatest overall reduction in leachable $\mathrm{Cu}$ was given by $\mathrm{BC} 1(3 \%)$. This amendment led to a $91 \%$ reduction in leachable $\mathrm{Cu}$ relative to the unamended samples. Compost alone (1\%) proved the least effective amendment; although leachable Cu was still reduced by $47 \%$. 


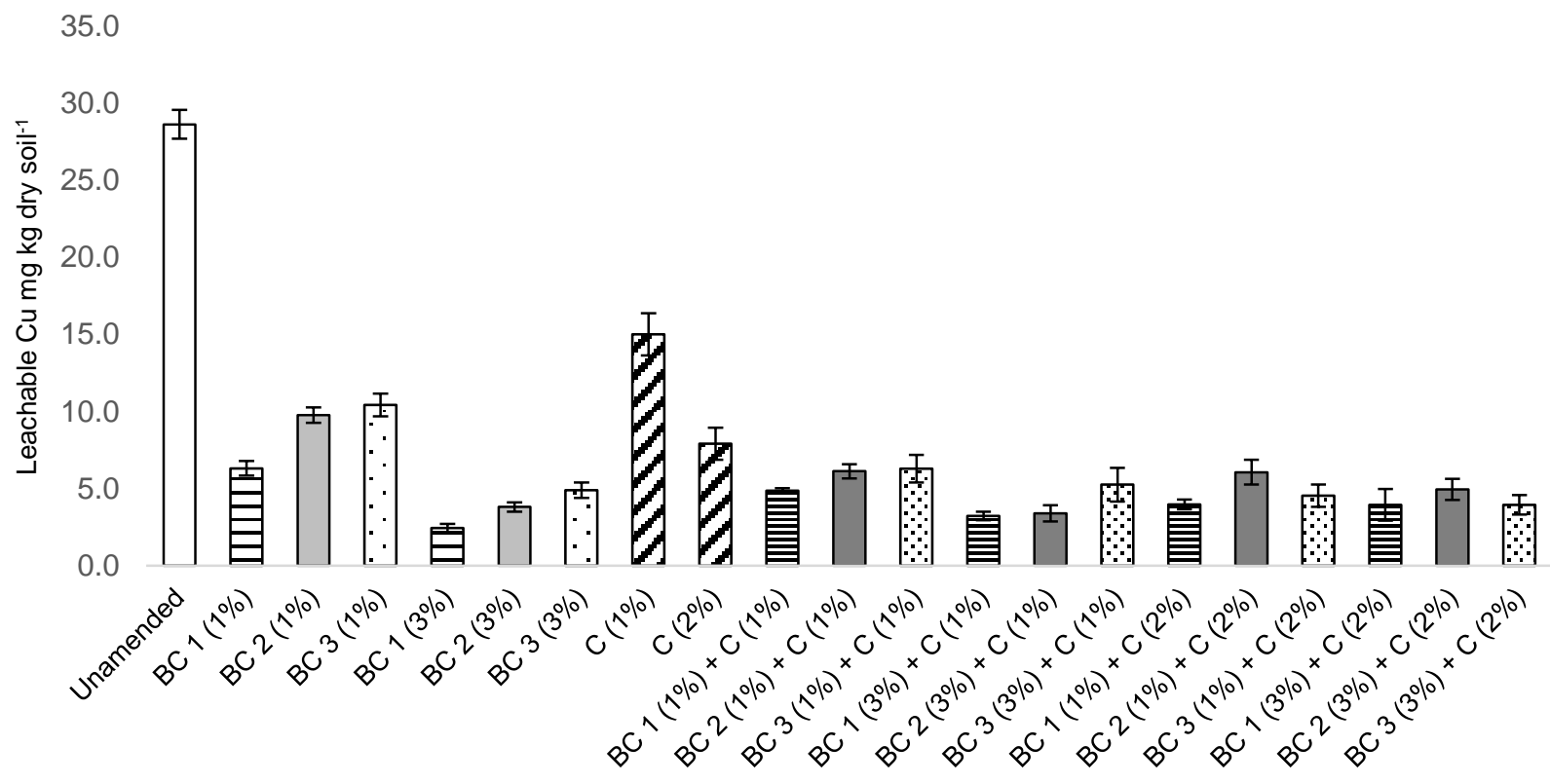

Figure 1: Mean concentration of leachable Cu mg kg${ }^{-1}$ in pre-incubation soils ( \pm standard error, $n=4$ ) (copyright $\mathrm{r} 3$ environmental technology uk Itd, 2015; reproduce by permission).

The results for leaching tests following incubation mirrored the pre-incubation leaching tests to some extent, with all amendments reducing mobile Cu relative to the unamended samples. However, the differences between biochars in terms of $\mathrm{Cu}$ immobilisation were less discernible post-incubation (see Figure 2). Similar to the pre-incubation leaching tests, significant differences were found between the amendments $(p<0.01)$. Additionally, the leachable $\mathrm{Cu}$ in the unamended samples decreased by $25 \%$ compared to pre-incubation. Mann-Whitney $U$ tests suggested that there were significant differences between pre- and post-incubation datasets (medians: $5.09 \mathrm{mg} \mathrm{kg}^{-1}$ and $4.13 \mathrm{mg} \mathrm{kg}^{-1}$ respectively, $\mathrm{p}=0.01$ ). 


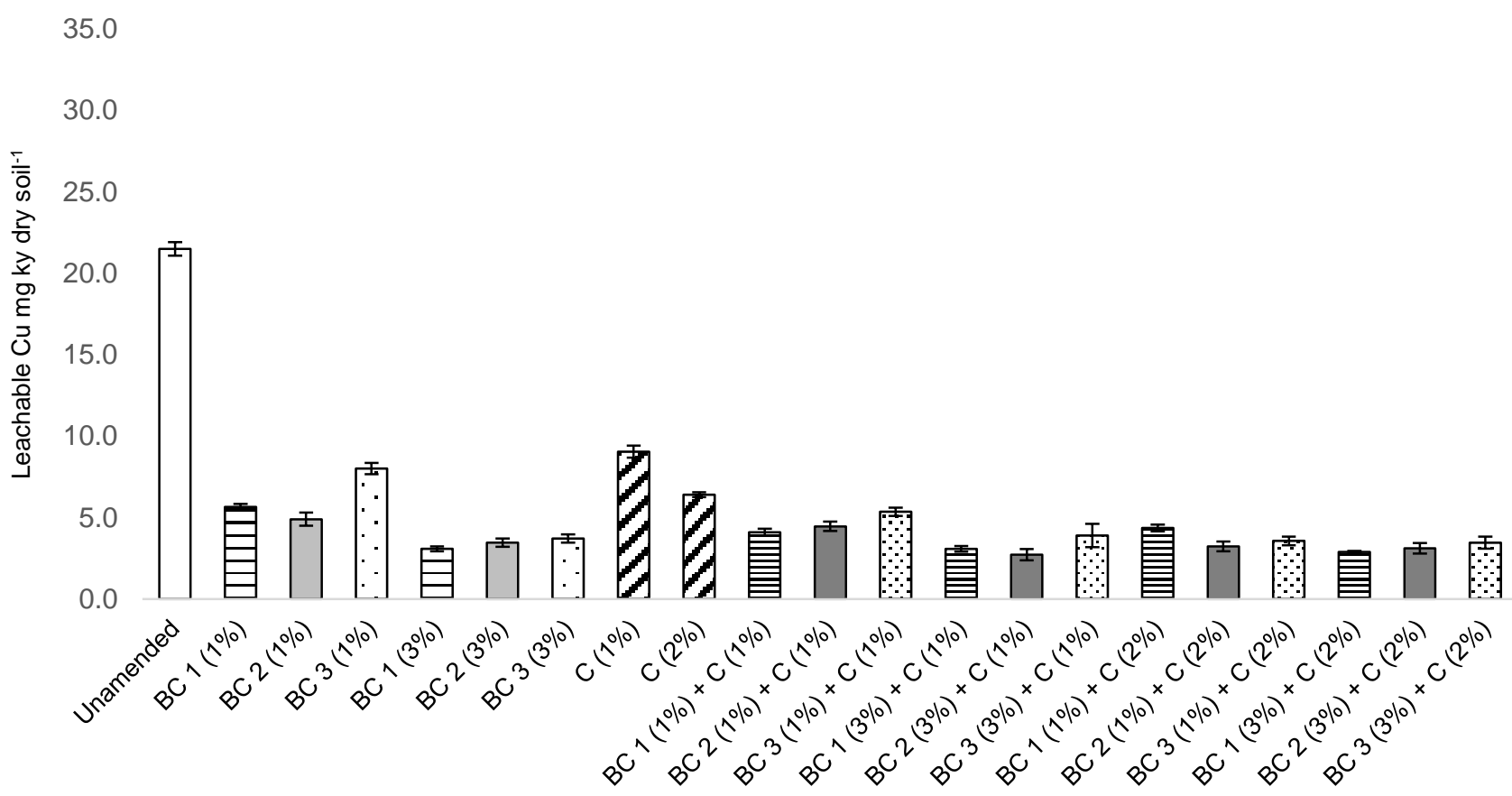

Figure 2: Mean concentration of leachable $\mathrm{Cu} \mathrm{mg} \mathrm{kg}^{-1}$ in post-incubation soils ( \pm standard error, $\mathrm{n}=4$ ) (copyright $r 3$ environmental technology uk Itd, 2015; reproduce by permission)

The leaching tests performed on soils taken from pots after a seven week (sunflower) growth period again showed a significant reduction in leachable $\mathrm{Cu}$ across all amendments compared to the unamended samples (see Figure $3)(\mathrm{p}<0.01)$. The largest decreases occurred in BC2 $(3 \%)+(1 \%)$ and $\mathrm{BC} 1(3 \%)+$ $(2 \%)$ with 2.76 and $2.92 \mathrm{mg} \mathrm{kg}^{-1}$ leachable Cu respectively, compared to $21.8 \mathrm{mg} \mathrm{kg}^{-}$ ${ }^{1}$ in the unamended. Mann-Whitney $U$ testing suggested there were no significant differences between leaching tests carried out in soils sieved to $2 \mathrm{~mm}$ compared to those sieved to $4 \mathrm{~mm}$. However, pre-incubation and post-growth $(2 \mathrm{~mm})$ leaching test datasets were found to be significantly different (medians: $5.09 \mathrm{mg} \mathrm{kg}^{-1}$ and $0.91 \mathrm{mg}$ $\mathrm{kg}^{-1}$ respectively, $\mathrm{p}<0.01$ ). 

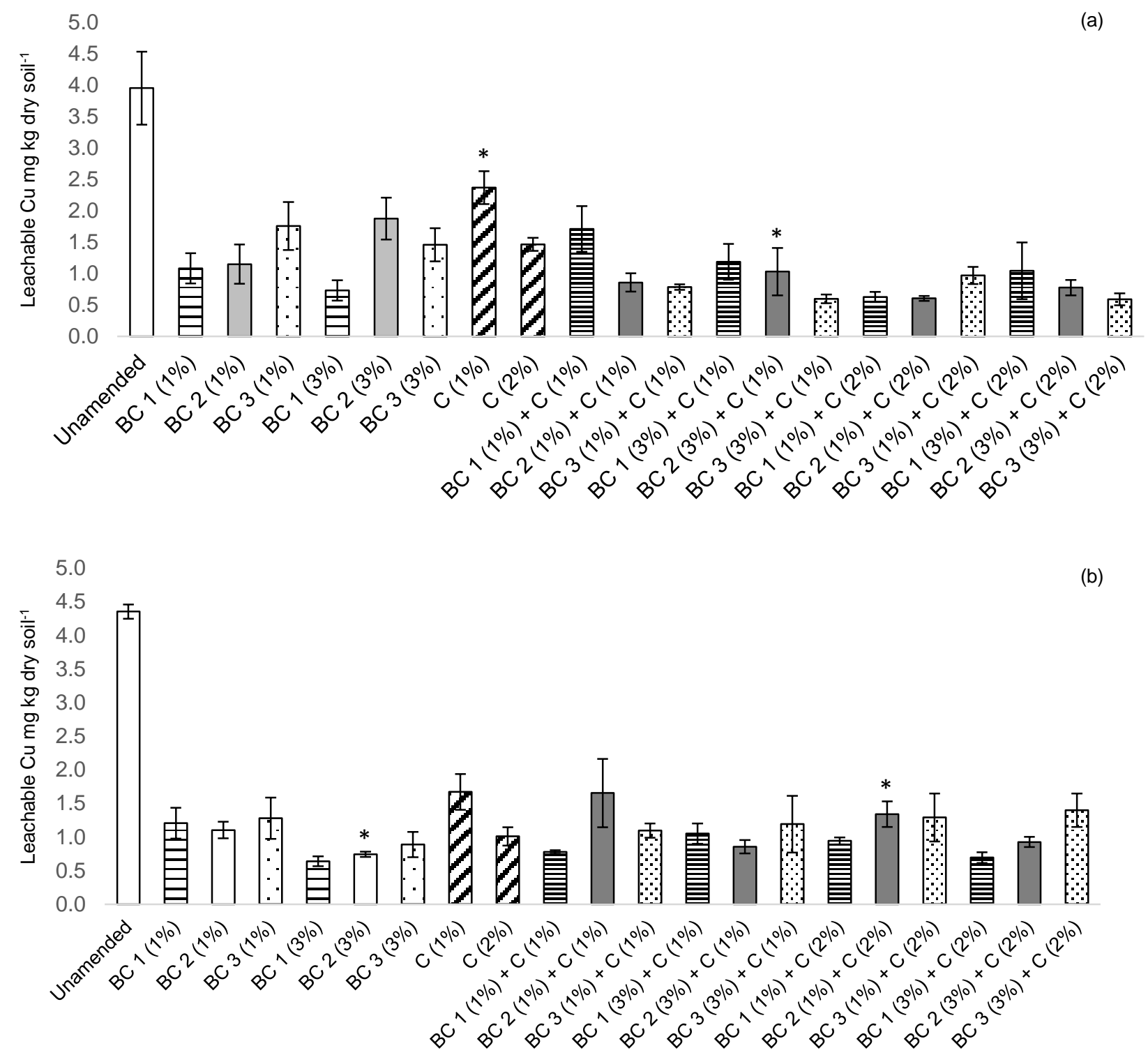

Figure 3: Mean concentration of leachable Cu mg kg${ }^{-1}$ in post-growth soils, sieved to $2 \mathrm{~mm}$ (a) and $4 \mathrm{~mm}$ (b) ( \pm standard error, $n=5$ ). *outlier (determined using Grubbs outlier test) has been removed: $n=4$. Note: change in $y$-axis scale (copyright $r 3$ environmental technology uk Itd, 2015; reproduce by permission)

A dramatic drop in leachable Cu was determined in the post-growth samples across all amendments and in the unamended samples; a mean reduction of $75 \%$ was found compared to pre-incubation leachable $\mathrm{Cu}$. Leachable $\mathrm{Cu}$ in the unamended samples decreased by $86 \%$ between the two sets of leaching tests, from $28.8 \mathrm{mg} \mathrm{kg}$ ${ }^{1}$ pre-incubation to $3.96 \mathrm{mg} \mathrm{kg}^{-1}$ post-growth $(4 \mathrm{~mm})$.

\section{$3.2 \quad \mathrm{pH} \& \mathrm{DOC}$}

Significant differences were found in soil $\mathrm{pH}$ between the amendments at each of the three time points $(p<0.01)$ but $\mathrm{pH}$ consistently increased in all amendments compared to the unamended soil (Figure 4Figure 5). However, soil pH varied less between amendments post-growth compared to the pre- and post-incubation tests. 
Overall, $\mathrm{BC} 1(3 \%)$ amendments with and without compost were associated with the greatest $\mathrm{pH}$ increases. Rank Spearman testing found a negative correlation between $\mathrm{pH}$ and leachable Cu pre-incubation. This was found to be significant $(r=-0.85$, $\mathrm{p}<0.01)$. Post-incubation $\mathrm{pH}$ also had a significant negative correlation with leachable $\mathrm{Cu}(\mathrm{r}=-0.84, \mathrm{p}<0.01)$. No significant relationship was found between $\mathrm{pH}$ and leachable $\mathrm{Cu}$ post-growth. Mann-Whitney $U$ testing determined a significant difference between pre- and post-growth $\mathrm{pH}$ (Medians: 7.33 and 7.64 respectively, $p<0.01$ ) as well as pre- and post-incubation (Medians: 7.33 and 7.41 respectively, $\mathrm{p}=0.01$ ).

Significant differences were found between amendments for DOC in solution across all time points (Figure 5, p<0.01). Pre-incubation DOC followed a similar trend to soil $\mathrm{pH}$ (and showed an inverse relationship with leachable $\mathrm{Cu}$ ), with $\mathrm{BC} 1(3 \%)$ with and without compost increasing DOC most greatly. A significant correlation was determined between DOC and $\mathrm{pH}$ pre-incubation (positive; $r=0.78, p<0.01$ ) and leachable Cu pre-incubation (negative; $r=-0.80, p<0.01$ ).

A significant overall increase was found in DOC between pre-incubation and postincubation (medians: $19.3 \mathrm{mg} \mathrm{kg}^{-1}$ and $29.0 \mathrm{mg} \mathrm{kg}^{-1}, \mathrm{p}<0.01$ ). A significant negative correlation was determined between post-incubation DOC and leachable $\mathrm{Cu}(\mathrm{r}=-$ $0.79, p<0.01$ ). No significant relationship could be established between post-growth DOC and leachable $\mathrm{Cu}$. However, post-growth DOC significantly increased compared to pre-growth DOC (medians: $19.3 \mathrm{mg} \mathrm{kg}^{-1}$ and $78.5 \mathrm{mg} \mathrm{kg}^{-1}, \mathrm{p}<0.01$ ). This shows a comparable but inverse trend to leachable $\mathrm{Cu}$, which overall significantly decreased post-growth.

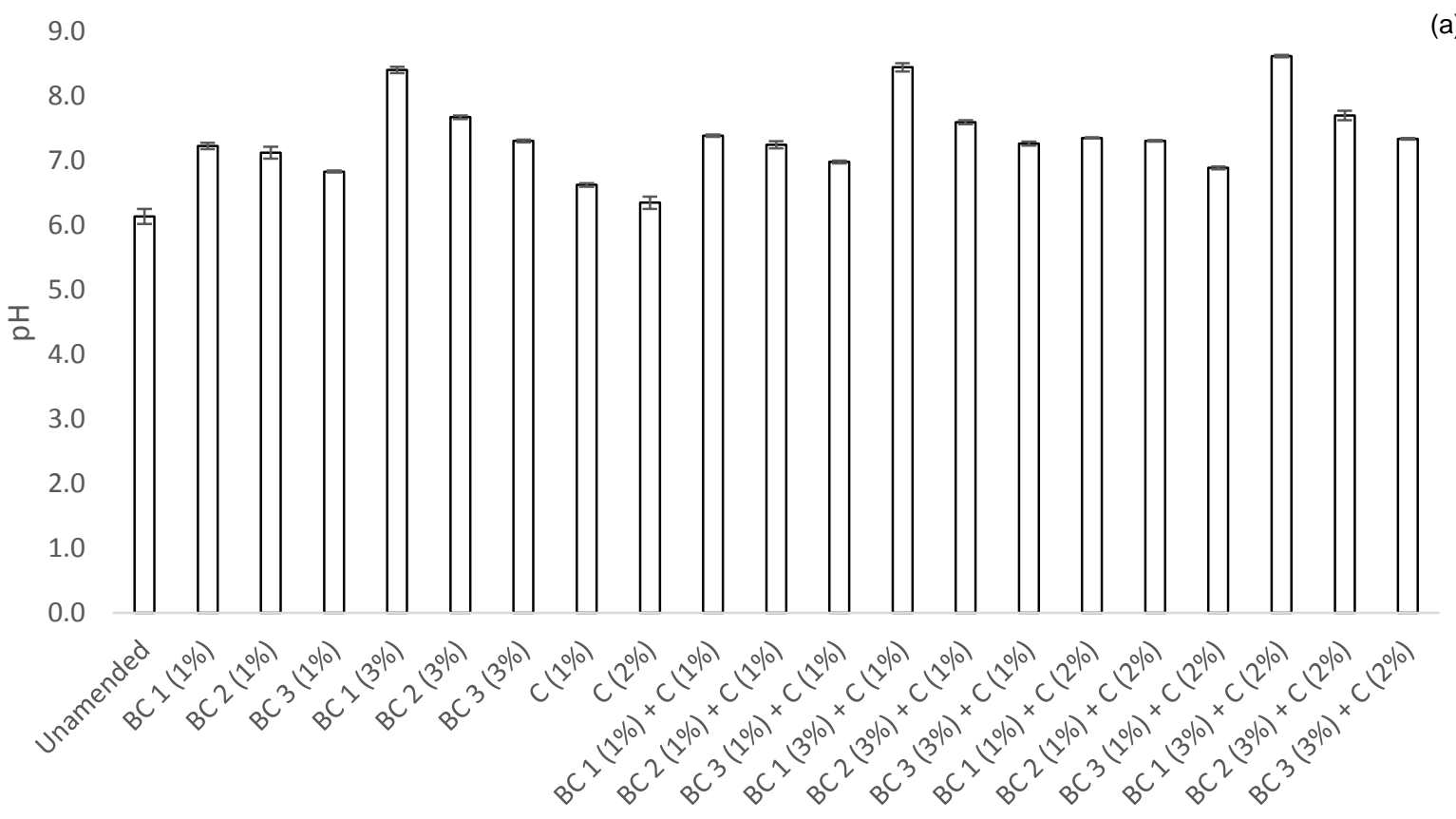



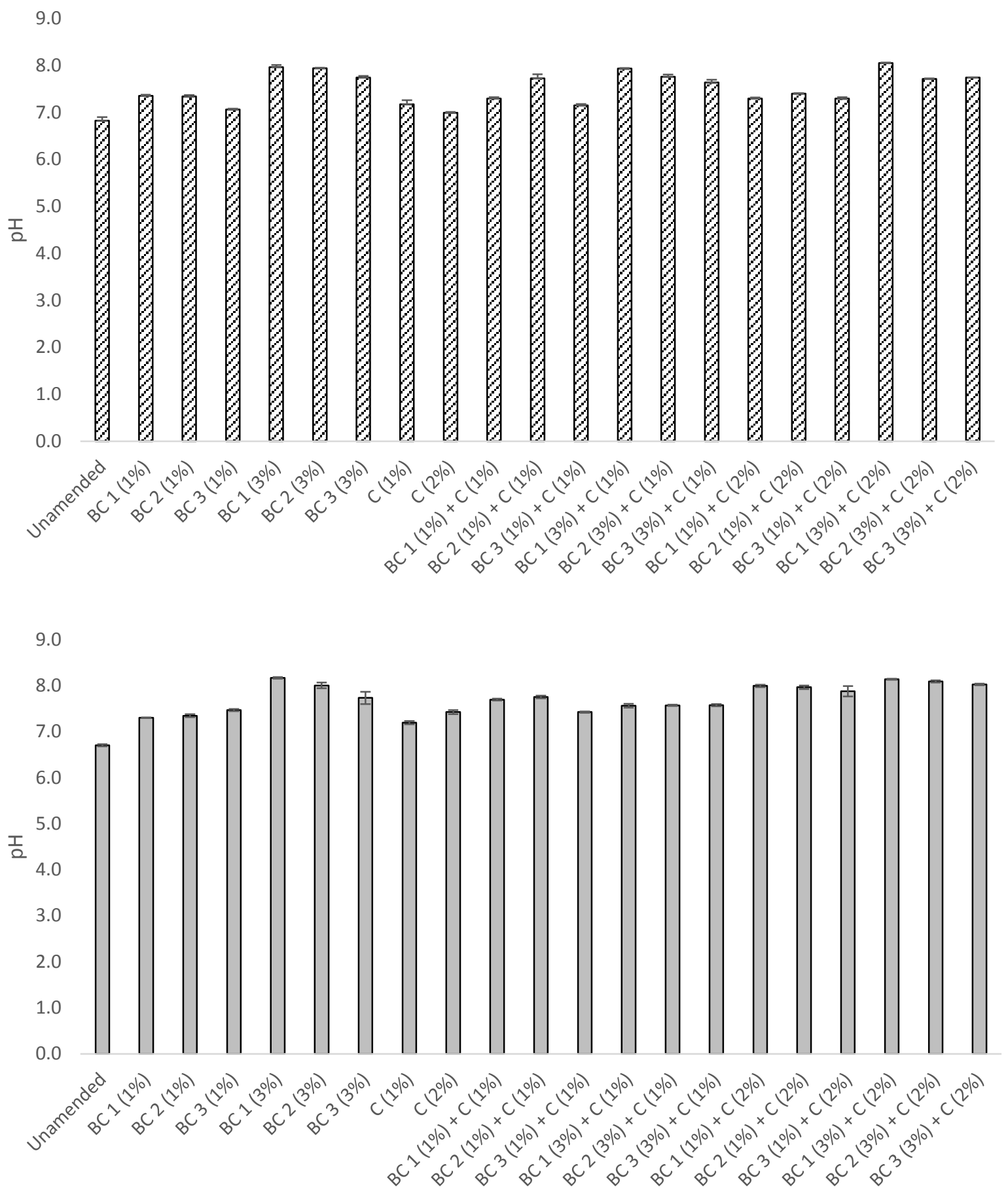

Figure 4: $\mathrm{pH} \pm$ standard error: pre-incubation (a), post-incubation (b) and post-growth (c), $n=3,3,5$ (copyright $\mathrm{r} 3$ environmental technology $\mathrm{uk}$ Itd, 2015; reproduce by permission) 


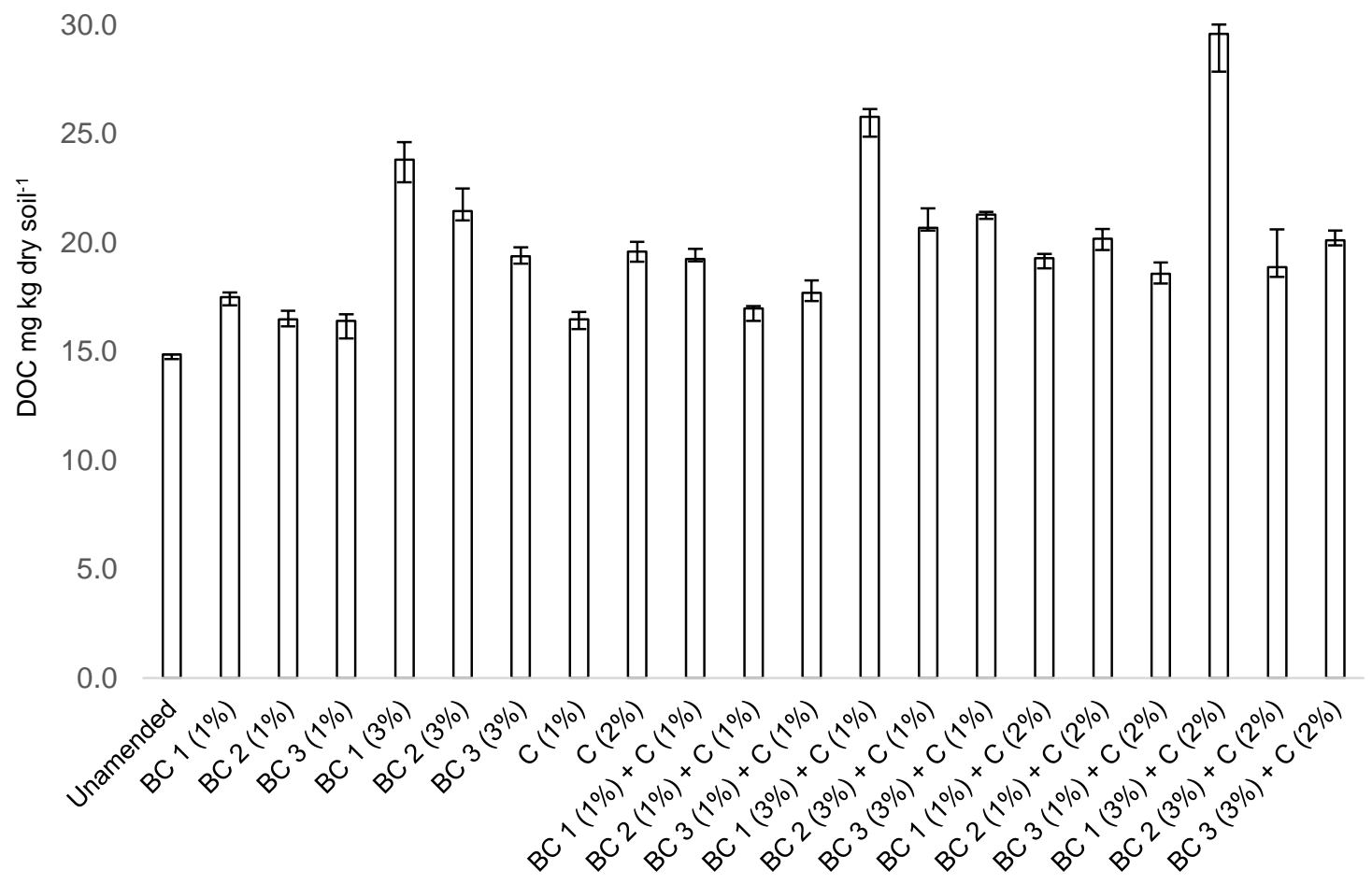

60.0

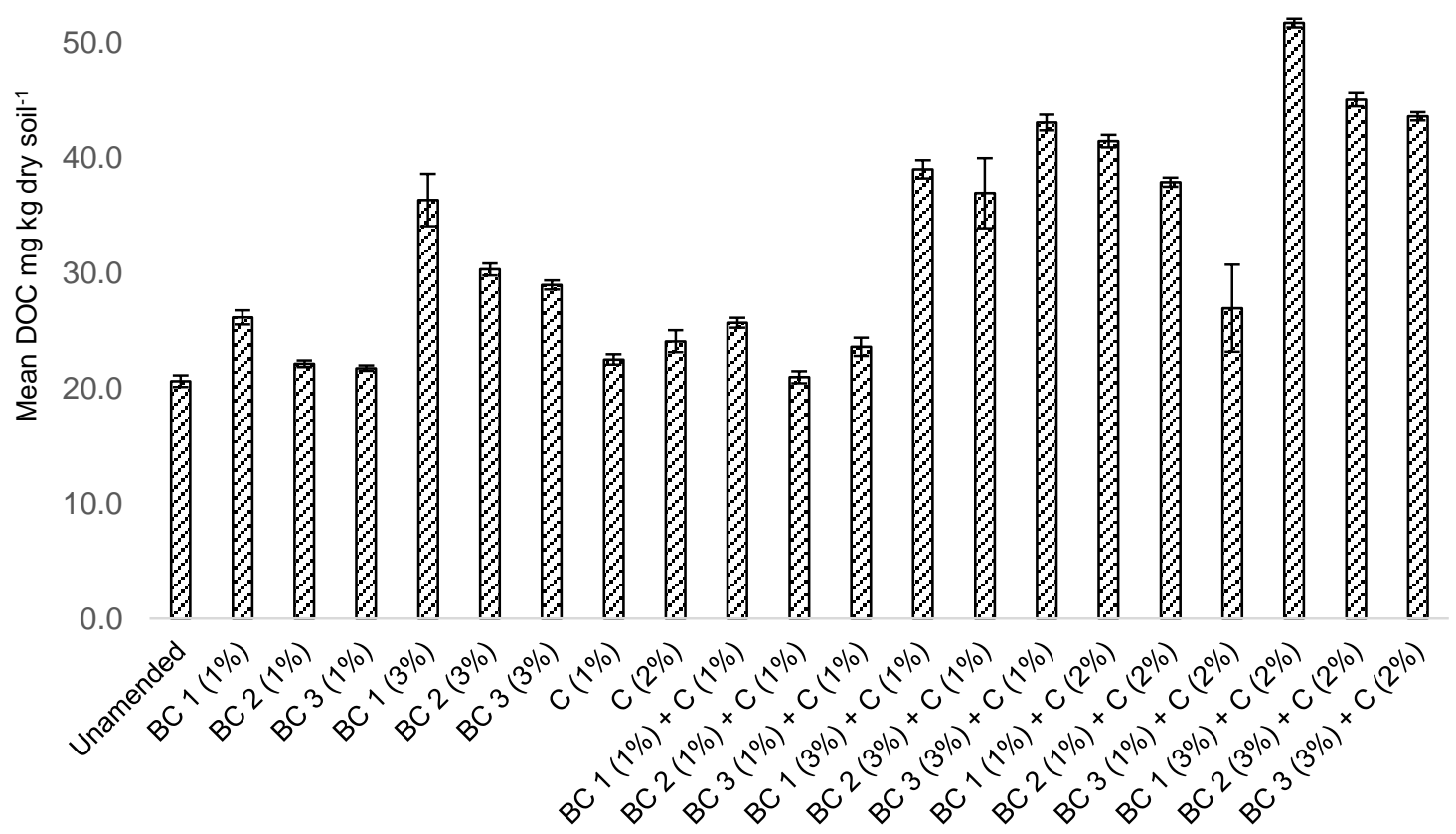




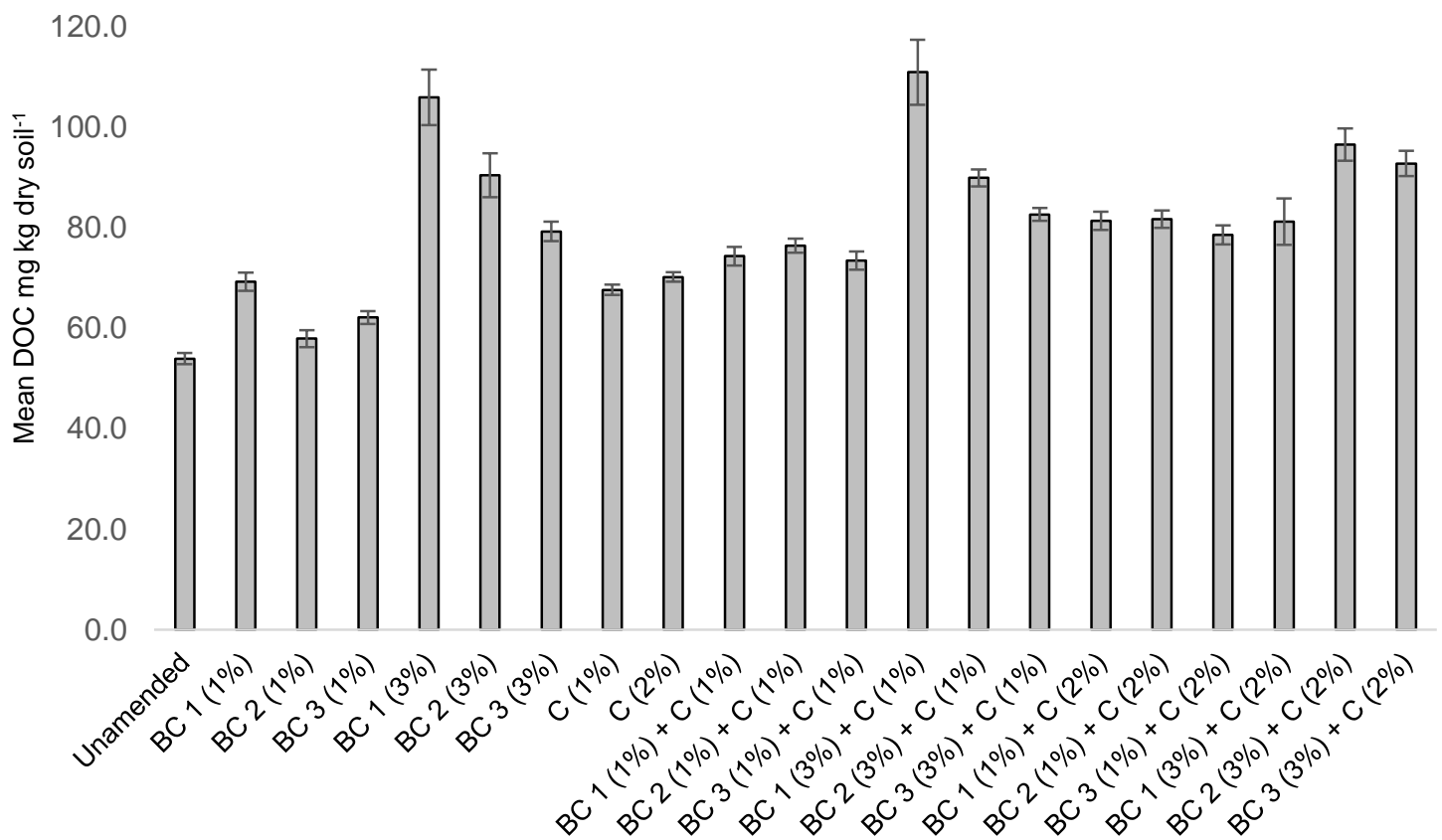

Figure 5: Mean DOC $\mathrm{mg} \mathrm{kg}^{-1} \pm$ standard error: pre-incubation (a), post-incubation (b) and post-growth (c), $n=3,3,5$. Note - change in $y$-axis scales (copyright $r 3$ environmental technology uk Itd, 2015; reproduce by permission)

\subsection{Plant Trials}

\subsubsection{Plant Height}

Significant differences were found between amendments for both plant height and root length $(p<0.01)$. Sunflower height over the seven week growth period was greatest in soils amended with $\mathrm{BC} 1(3 \%)$ in combination with compost (Table 2). The most effective amendment $(\mathrm{BC} 1(3 \%)+\mathrm{C}(1 \%))$ improved plant height by around $36.5 \mathrm{~cm}$ and root length by around $9 \mathrm{~cm}$ relative to the unamended samples. At the lower rate of biochar application (1\%), compost addition had a greater impact on the plant height of the $\mathrm{BC} 2$ and $\mathrm{BC} 3$ plants compared to the $\mathrm{BC} 1$ samples, with compost addition at $(2 \%)$ doubling plant height for these two biochars. Plant height and root length were severely reduced in the unamended soils compared with all of the amended samples. 
Table 2: Mean values of plant height and root length in the amendments ( \pm standard error, $n=5$ ).

\begin{tabular}{ccccc} 
Amendment & $\begin{array}{c}\text { Mean Plant height } \\
\text { (cm) } \begin{array}{c}\text { standard } \\
\text { error }\end{array}\end{array}$ & $\begin{array}{c}\text { Mean Root length } \\
\text { (cm) } \begin{array}{c}\text { standard } \\
\text { error }\end{array}\end{array}$ \\
\hline Unamended & 4.6 & \pm 0.9 & 2.0 & \pm 0.3 \\
BC 1 (1\%) & 23 & \pm 1.4 & 4.1 & \pm 0.5 \\
BC 2 (1\%) & 14 & \pm 0.8 & 7.6 & \pm 2.7 \\
BC 3 (1\%) & 9.9 & \pm 0.7 & 3.2 & \pm 0.7 \\
BC 1 (3\%) & 32 & \pm 3.3 & 11 & \pm 2.2 \\
BC 2 (3\%) & 18 & \pm 4.6 & 6.2 & \pm 1.2 \\
BC 3 (3\%) & 23 & \pm 2.3 & 6.7 & \pm 1.5 \\
C (1\%) & 11 & \pm 0.9 & 2.8 & \pm 0.1 \\
C (2\%) & 25 & \pm 2.2 & 4.7 & \pm 1.1 \\
BC 1 (1\%) + C (1\%) & 25 & \pm 3.6 & 4.7 & \pm 1.1 \\
BC 2 (1\%) + C (1\%) & 26 & \pm 3.6 & 7.5 & \pm 1.5 \\
BC 3 (1\%) + C (1\%) & 13 & \pm 1.2 & 2.9 & \pm 0.4 \\
BC 1 (3\%) + C (1\%) & 43 & \pm 1.5 & 11 & \pm 1.5 \\
BC 2 (3\%) + C (1\%) & 28 & \pm 2.4 & 12 & \pm 2.5 \\
BC 3 (3\%) + C (1\%) & 33 & \pm 4.6 & 5.7 & \pm 0.9 \\
BC 1 (1\%) + C (2\%) & 27 & \pm 2.0 & 5.4 & \pm 1.3 \\
BC 2 (1\%) + C (2\%) & 30 & \pm 1.7 & 5.6 & \pm 1.3 \\
BC 3 (1\%) + C (2\%) & 27 & \pm 2.1 & 7.5 & \pm 1.5 \\
BC 1 (3\%) + C (2\%) & 40 & \pm 2.3 & 15 & \pm 2.8 \\
BC 2 (3\%) + C (2\%) & 29 & \pm 2.1 & 9.3 & \pm 1.1 \\
BC 3 (3\%) + C (2\%) & 34 & \pm 3.6 & 8.4 & \pm 1.9 \\
\hline
\end{tabular}

\subsubsection{Plant Biomass}

Kruskal-Wallis testing found significant differences between amendments for both shoot and root dry biomass (Figure 6) $(p<0.01)$. Mirroring plant height data, the most notable increases in shoot biomass were achieved in $\mathrm{BC} 1(3 \%)$, with and without compost. For example, BC1 $(3 \%)+C(1 \%)$ yielded on average $0.2 \mathrm{~g}$ more shoot biomass than $\mathrm{BC} 2$ or $\mathrm{BC} 3$ with compost at equivalent application rates $(68 \%$ and $74 \%$ increase, respectively). BC3 amended soils generally resulted in the lowest shoot biomass increases relative to the unamended soils, however, BC3 achieved a greater shoot biomass yield than BC2 at 3\% both as a single amendment, and with $2 \%$ compost.

Even at the lower amendment rate, the compost only amendment increased shoot yields comparably to the lower rate of biochar application. These results are contrary to the leaching test results, where compost only amendments were found to be less effective than biochar only amendments. For the root dry biomass, there was less variation between amended and unamended samples and between the different 
amendments. Nonetheless, the general trend showed that combined amendments and higher application rates improved root biomass yields.

Rank Spearman testing determined that there was a significant positive correlation between shoot biomass and plant height $(r=0.89, p<0.01)$. No significant relationship was found between shoot biomass and post-growth leachable $\mathrm{Cu}$ in soil.

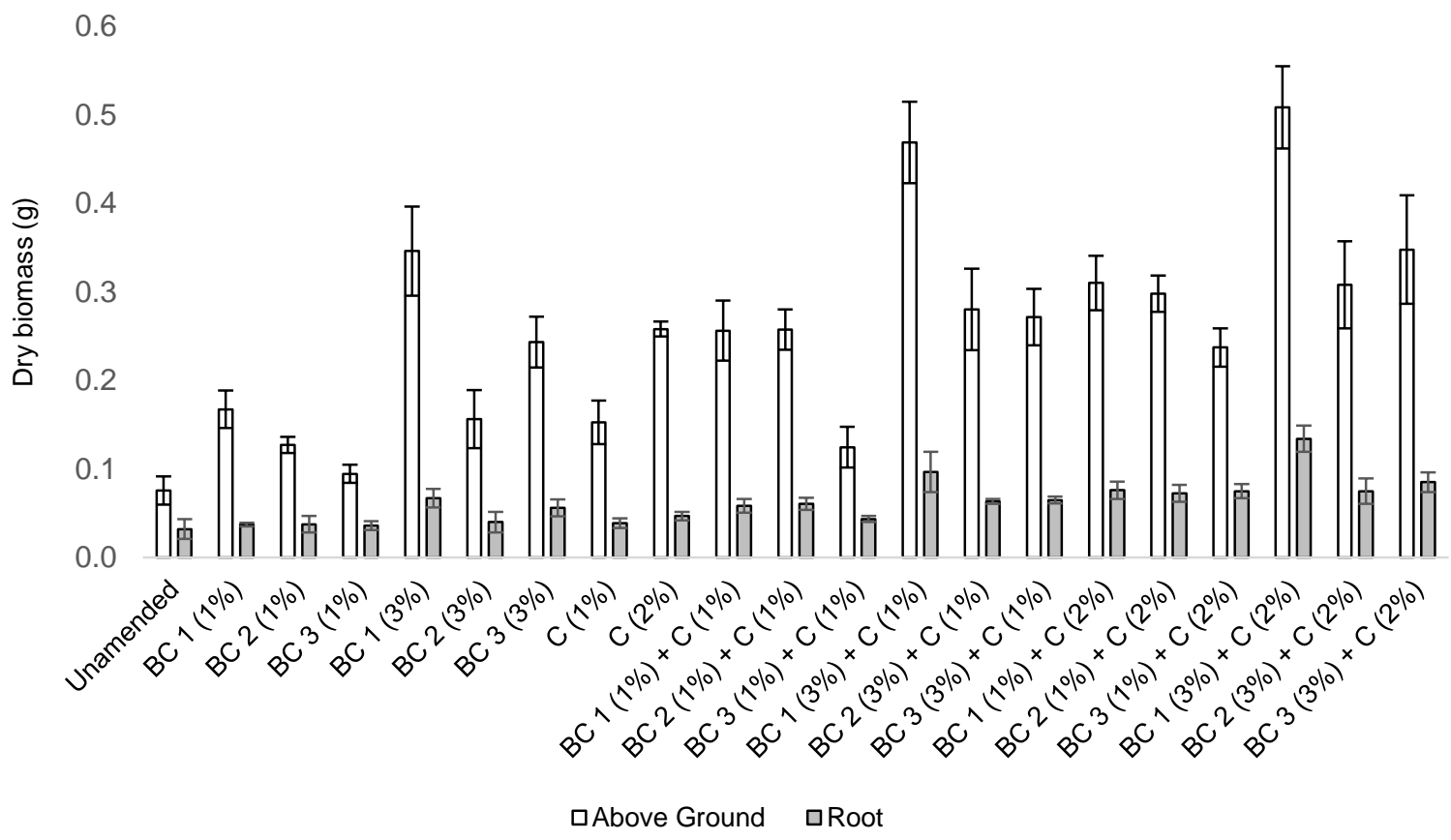

Figure 6: Mean Dry Biomass ( $g$ ), shoots and roots ( \pm standard error, $n=5$ ) (copyright $r 3$ environmental technology uk Itd, 2015; reproduce by permission)

\subsubsection{Plant Cu Concentrations}

Significant differences, established via Kruskal-Wallis testing, were determined between amendments for $\mathrm{Cu}$ concentration in both the shoot biomass $(p<0.01)$ and root biomass $(p<0.01)$. There was less of a clear trend in the data compared to previous data sets (Figure 7). However, higher application rates and combined amendments overall reduced the Cu concentration in the plant root and shoot biomass. Cu concentration was many times higher in the root samples compared to the shoot plant parts.

A significant negative correlation was determined between plant $\mathrm{Cu}$ concentration and plant biomass for both leaf $(r=-0.72, p<0.01)$ and stem data $(r=-0.84, p<0.01)$. No relationship was determined between these two variables for the root samples. 


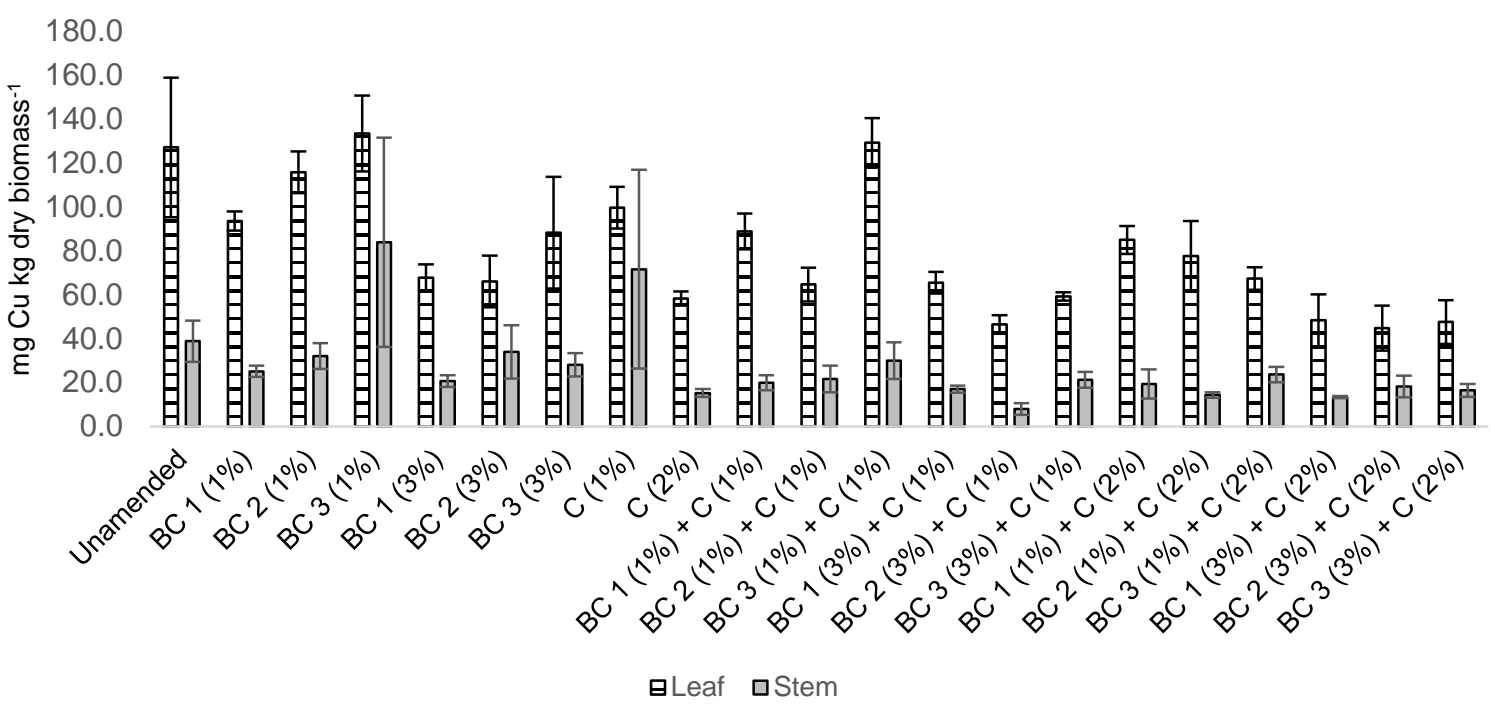

(a)

3500.0

(b)

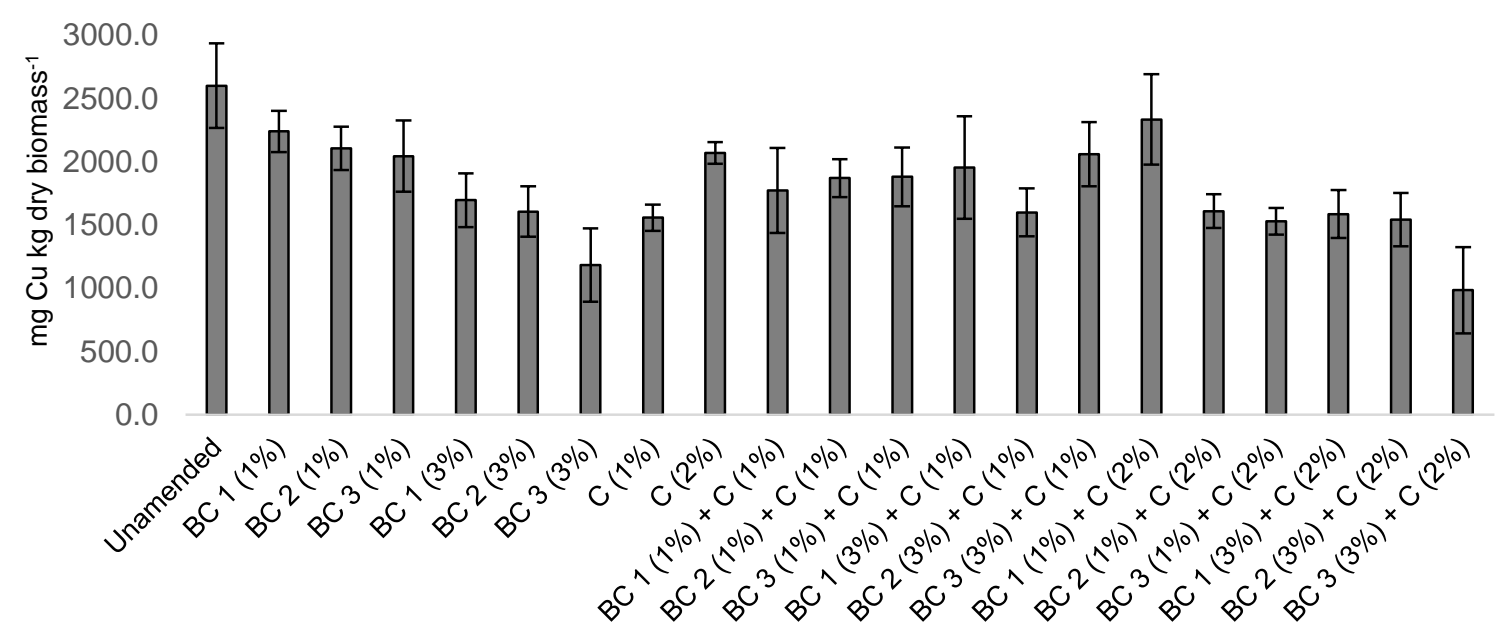

Figure 7: Mean Cu concentrations $\mathrm{mg} \mathrm{kg}^{-1}$ in plant dry biomass: shoots (a) and roots (b) ( \pm standard error, $n=5$ ) (copyright $r 3$ environmental technology uk Itd, 2015; reproduce by permission).

\subsubsection{Plant Nutrient Concentrations}

Kruskal-Wallis testing determined significant differences between treatments for measured nutrient concentrations in plant shoots, including calcium $(\mathrm{Ca})(\mathrm{p}<0.01)$, iron $(\mathrm{Fe})(\mathrm{p}<0.01)$, potassium $(\mathrm{K})(\mathrm{p}<0.01)$, magnesium $(\mathrm{Mg})(\mathrm{p}=0.02)$, and phosphorus $(P)(p<0.01)$. Nutrient concentrations in the shoot biomass were generally higher in the amended samples than in the unamended soil (Table 3). Overall, higher application rates of biochar and compost increased measured nutrient concentrations. BC1 amended shoots generally had the highest concentration of $\mathrm{Mg}$ and $\mathrm{K}$. The three biochars were largely comparable in terms of shoot $\mathrm{Ca}, \mathrm{Fe}$ and $\mathrm{P}$ concentrations. Compost only amendments generally had higher shoot nutrient concentrations than the lower application rate of biochar, however with the higher rate of biochar application, nutrient concentrations were largely comparable to, or better than, compost. 
Table 3: Mean nutrient concentrations $\mathrm{mg} \mathrm{kg}^{-1}$ in shoot dry biomass ( \pm standard error, $\mathrm{n}=5$ )

\begin{tabular}{|c|c|c|c|c|c|c|c|c|c|c|}
\hline \multirow{2}{*}{$\begin{array}{c}\text { Amendment } \\
\text { Unamended }\end{array}$} & \multicolumn{2}{|c|}{$\mathrm{Ca}(\mathrm{g} / \mathrm{kg})$} & \multicolumn{2}{|c|}{$\mathrm{Fe}(\mathrm{g} / \mathrm{kg})$} & \multicolumn{2}{|c|}{$\mathrm{K}(\mathrm{g} / \mathrm{kg})$} & \multicolumn{2}{|c|}{$\mathrm{Mg}(\mathrm{g} / \mathrm{kg})$} & \multicolumn{2}{|c|}{$P(g / k g)$} \\
\hline & 6.41 & \pm 1.34 & 0.25 & \pm 0.05 & 6.32 & \pm 1.84 & 3.74 & \pm 0.87 & 4.18 & \pm 1.34 \\
\hline BC1 (1\%) & 10.8 & \pm 1.83 & 0.12 & \pm 0.15 & 42.8 & \pm 5.05 & 2.69 & \pm 0.22 & 1.92 & \pm 0.18 \\
\hline BC2 (1\%) & 9.32 & \pm 1.07 & 0.16 & \pm 0.21 & 27.4 & \pm 2.40 & 2.97 & \pm 0.66 & 2.32 & \pm 0.21 \\
\hline BC3 (1\%) & 11.8 & \pm 2.91 & 0.44 & \pm 0.93 & 24.6 & \pm 4.40 & 4.28 & \pm 0.48 & 2.87 & \pm 0.19 \\
\hline BC1 (3\%) & 25.8 & \pm 1.54 & 0.10 & \pm 0.11 & 92.6 & \pm 7.41 & 5.00 & \pm 0.20 & 4.80 & \pm 0.37 \\
\hline BC2 (3\%) & 21.3 & \pm 4.35 & 0.26 & \pm 0.13 & 57.7 & \pm 7.74 & 4.03 & \pm 0.55 & 3.03 & \pm 0.30 \\
\hline BC3 (3\%) & 28.5 & \pm 11.2 & 0.22 & \pm 0.77 & 70.1 & \pm 20.9 & 5.36 & \pm 1.26 & 3.20 & \pm 0.82 \\
\hline Compost (1\%) & 12.9 & \pm 2.31 & 0.29 & \pm 0.73 & 9.95 & \pm 2.88 & 3.65 & \pm 0.59 & 2.35 & \pm 0.42 \\
\hline Compost (2\%) & 19.4 & \pm 4.28 & 0.16 & \pm 0.16 & 20.2 & \pm 4.00 & 4.72 & \pm 0.53 & 1.70 & \pm 0.28 \\
\hline $\mathrm{BC} 1(1 \%)+\mathrm{C}(1 \%)$ & 14.4 & \pm 1.31 & 0.15 & \pm 0.21 & 42.4 & \pm 5.82 & 3.00 & \pm 0.40 & 1.99 & \pm 0.22 \\
\hline BC2 $(1 \%)+C(1 \%)$ & 17.7 & \pm 4.33 & 0.15 & \pm 0.14 & 35.1 & \pm 2.54 & 2.99 & \pm 0.43 & 1.69 & \pm 1.00 \\
\hline BC3 $(1 \%)+C(1 \%)$ & 8.35 & \pm 0.47 & 0.31 & \pm 0.42 & 23.4 & \pm 2.30 & 2.69 & \pm 0.07 & 1.94 & \pm 0.13 \\
\hline $\mathrm{BC} 1(3 \%)+\mathrm{C}(1 \%)$ & 26.5 & \pm 1.34 & 0.11 & \pm 0.19 & 88.5 & \pm 9.86 & 4.50 & \pm 0.20 & 4.32 & \pm 0.55 \\
\hline BC2 (3\%) + C (1\%) & 24.2 & \pm 4.68 & 0.98 & \pm 0.14 & 48.3 & \pm 3.42 & 3.80 & \pm 0.31 & 2.50 & \pm 0.22 \\
\hline BC3 $(3 \%)+C(1 \%$ & 30.0 & \pm 3.60 & 0.12 & \pm 0.24 & 51.1 & \pm 5.27 & 4.09 & \pm 0.41 & 2.75 & \pm 0.27 \\
\hline BC1 $(1 \%)+C(2 \%)$ & 21.1 & \pm 3.12 & 0.13 & \pm 0.20 & 45.5 & \pm 8.03 & 3.38 & \pm 0.57 & 1.79 & \pm 0.22 \\
\hline BC2 (1\%) + C (2\%) & 25.1 & \pm 4.09 & 0.17 & \pm 0.51 & 45.9 & \pm 4.84 & 3.90 & \pm 0.70 & 2.29 & \pm 0.29 \\
\hline BC3 $(1 \%)+C(2 \%)$ & 18.3 & \pm 2.35 & 0.16 & \pm 0.16 & 43.9 & \pm 8.53 & 2.99 & \pm 0.20 & 2.00 & \pm 0.05 \\
\hline BC1 $(3 \%)+C(2 \%)$ & 27.4 & \pm 7.84 & 0.06 & \pm 0.01 & 69.3 & \pm 7.41 & 4.14 & \pm 0.76 & 3.46 & \pm 0.47 \\
\hline BC2 (3\%) + C (2\%) & 21.9 & \pm 6.00 & 0.10 & \pm 0.02 & 53.1 & \pm 7.75 & 3.78 & \pm 0.59 & 2.78 & \pm 0.34 \\
\hline BC3 $(3 \%)+C(2 \%)$ & 24.4 & \pm 5.58 & 0.11 & \pm 0.06 & 51.3 & \pm 5.48 & 3.89 & \pm 0.53 & 2.52 & \pm 0.36 \\
\hline
\end{tabular}

\section{Discussion}

\subsection{Effects of Amendments on Cu Leachability}

Our results are in accordance with previous findings (Venegas et al., 2015; Houben et al., 2013; Khan et al., 2013; Park et al., 2011; Sizmur et al., 2011). We found a significant decrease in leachable $\mathrm{Cu}$ associated with application of all three biochars relative to the unamended samples. $\mathrm{BC} 1$ was generally the most effective biochar in terms of $\mathrm{Cu}$ immobilisation, but after incubation and plant growth differences between $\mathrm{BC} 1, \mathrm{BC} 2$ and $\mathrm{BC} 3$ were less pronounced. This suggests the effects of time and soil reactions are important factors to consider when measuring the effectiveness of soil amendments on TE concentrations. $\mathrm{Fe}_{2} \mathrm{O}_{3}$ (haematite) amended BC3 was the least effective biochar for immobilising Cu contrary to initial expectations.

Compost was also shown to significantly reduce leachable $\mathrm{Cu}$ compared to the unamended samples, although not as well as biochar. However, there was a general trend that application of biochar and compost combined enhanced $\mathrm{Cu}$ immobilisation. Combined application with compost was especially effective at the lower rate of biochar addition. Leachable $\mathrm{Cu}$ is likely to have decreased in the presence of compost due to Cu's well-documented strong affinity for OM (Kumpiene et al., 2008).

Notable differences were determined between the three time points in terms of leachable $\mathrm{Cu}$, with a dramatic drop for all amendments post-growth. It is possible for plant growth to decrease Cu solubility in soils (Römkens et al., 1999). However, 
there was also reduction in leachable $\mathrm{Cu}$ in the unamended samples, in which plant growth, especially root growth, was very stunted. It is unlikely therefore that the reduction in leachable $\mathrm{Cu}$ is attributable solely to plant growth effects. Additionally, the $\mathrm{Cu}$ concentrations in the plant shoot and root biomass were an order of magnitude less than the leachable $\mathrm{Cu}$ found in soil and therefore not substantial enough in any of the amendments to account for such a significant drop in $\mathrm{Cu}$.

For both pre- and post-incubation leaching tests, soil pH was negatively correlated with $\mathrm{Cu}$ leachability. $\mathrm{pH}$ is a well-documented driver of metal availability in soil (Kong et al., 2014), including Cu availability (Kumpiene et al., 2008). Although significant differences were found in $\mathrm{pH}$ pre-incubation and post-growth $(2 \mathrm{~mm})$, there was however a median difference of less than one $\mathrm{pH}$ point between the two datasets. It is therefore unlikely that the difference in $\mathrm{pH}$ could account for the aforementioned decrease in leachable Cu post-growth.

DOC increases were measured for biochar and compost applications in this study; organic amendments are known to increase DOC in soils (Cao et al., 2003; Antoniadis \& Alloway, 2002). Beesley et al. (2010) also found increased DOC associated with the application of biochar and green waste compost amendments to soil. Our study showed DOC was significantly increased post-growth compared to pre-growth. Plant growth is known to increase DOC in soils (Römkens et al., 1999), as a result of root exudates. However, in this study, the increase occurred across all amendments and the unamended samples. As plant growth was very limited in the unamended samples, it seems unlikely that plant-growth derived DOC caused the post-growth reduction in leachable $\mathrm{Cu}$. In addition, the significant difference in DOC post-growth combined with a decrease in leachable Cu contrasts with the established nature of DOC-metal interactions. DOC is generally regarded as mobilising soil $\mathrm{Cu}$, as a result of DOC competing with metals for sorption sites or by forming complexes with the metal ions, preventing sorption of metals onto sequestering surfaces (Chirenje et al., 2002; Redman et al., 2002; Weng et al., 2002; Giusquiani et al., 1998).

Instead, the observed drop in leachable Cu post-incubation and post-growth could be explained by rewetting processes. Wenzel and Blum (1999) highlight that airdrying soils prior to analysis of mobile metal content can result in the overestimation of metal concentrations, including $\mathrm{Cu}$. Haynes and Swift (1991) demonstrated that air drying soils increased the Cu extractability, but that this effect was reversible; after a two week incubation period following rewetting, Cu extractability had decreased to a level comparable to pre-drying. This trend was attributed to metalretaining organo-mineral associations being disrupted and then reformed by drying and subsequent rewetting. It is possible then, that the initial leaching test results showed unrealistically high $\mathrm{Cu}$ concentrations as a result of this process. The decrease in $\mathrm{Cu}$ found in the post-growth leaching tests could accordingly be attributed to an extended period following rewetting allowing the establishment of more stable metal organo-mineral associations.

Nonetheless, even if the unamended soil in the post-growth leaching tests is accepted as giving a "true" representation of leachable $\mathrm{Cu}$ in the soil, the effects of 
biochar and compost are still substantial; a clear reduction in leachable Cu was obtained in the post-growth amended soils compared to the unamended samples.

\subsection{Effects of Amendments on Plant Growth and $\mathrm{Cu}$ Concentration}

All biochar and compost amendments improved sunflower growth relative to the unamended samples, mirroring previous findings (Buss et al., 2012; Beesley et al., 2010). Improved plant growth in Cu contaminated soils with biochar and compost addition may be the result of several factors including decreased Cu bioavailability in the soil (at each time point, all amendments decreased leachable $\mathrm{Cu}$ in the soil) and improved soil nutrient and water provision resulting from amendment incorporation into the soil (Bruun et al., 2014; Basso et al., 2013).

The greatest increases in shoot yield were observed in the BC1 amendments at the higher application rate; $\mathrm{BC} 1$ amended soil had notably improved growth compared to the other biochars or compost as a single amendment. As the leaching tests suggested that over time differences between biochars became less significant, it is probable that an alternate factor caused the disparity between $\mathrm{BC} 1$ and the other two biochars in terms of plant growth. It is possible that differences in nutrient provision between the three biochars was a contributing factor in plant yields. Indeed, Alburquerque et al. (2014) found sunflower yields were improved in OM poor, low nutrient, loamy sand by amendment depending on biochar type (in terms of nutrient content) and application rate. In our study, some available nutrients were increased in $\mathrm{BC} 1$ compared to the other biochars (see supplementary materials http://doi.pangaea.de/10.1594/PANGAEA.846932). For example, BC1 generally had the highest concentration of the three biochars of exchangeable cations including $\mathrm{Ca}, \mathrm{Mg}$ and $\mathrm{K}$. Ca may compete with Cu for plant uptake (Fan et al., 2012).

Additionally, plant biomass concentrations of certain nutrients were greater for BC1 amendments. For example, plants grown in soils amended with BC1 (3\%), as well as having higher overall biomass, had an average of $92.6 \mathrm{~g} \mathrm{~K} \mathrm{~kg}^{-1}$ in shoot dry biomass, compared to $70.1 \mathrm{~g} \mathrm{~K} \mathrm{~kg}^{-1}$ in BC3 (3\%) plants, or $57.7 \mathrm{~g} \mathrm{~K} \mathrm{~kg}^{-1}$ in BC2 (3\%).

Compost addition as a single amendment also improved shoot yields comparably to biochar only amendments (in contrast to leaching test results). Additionally, compost further improved the effectiveness of the biochar when applied together. The nutrient provision effects of compost are well established and compost has been shown to improve many soil characteristics, including soil structure and water retention, which can lead to improved yields (Ohsowski et al., 2012; Evanylo et al., 2008; Hargreaves et al., 2008; Aggelides and Londra, 2000). However, the compost used in our research had relatively low $\mathrm{OM}$ and plant nutrient levels. Potentially then, an even greater impact might have been seen if a higher-quality compost was used.

Most of the amendments tested significantly reduced $\mathrm{Cu}$ concentrations in plant shoots. Where compost and biochar were applied as single amendments, higher application rates decreased concentrations of $\mathrm{Cu}$ in plant shoots. Where biochars were applied in combination with compost, combinations mostly improved on the results of single amendments. Kolbas et al. (2014) state that Cu availability to plants 
may be influenced by a range of factors including soil type, $\mathrm{DOC}$, and $\mathrm{pH}$ of soil pore waters; and the results of our study (see also supplementary materials http://doi.pangaea.de/10.1594/PANGAEA.846932) have shown that all of these factors were altered by biochar and compost additions to soil. In numerous studies, biochar addition has been found to decrease contaminant availability to plants (Khan et al., 2013; Cui et al., 2011; Park et al., 2011; Namgay et al., 2010). Kloss et al. (2014) found that four different biochar types all decreased Cu concentrations in plant tissue. Similar results have been reported for compost application to soil (Ruttens et al., 2006). Karami et al. (2011) showed that the addition of both biochar and compost significantly reduced shoot $\mathrm{Cu}$ concentrations in ryegrass in comparison to unamended soils.

\section{Conclusions}

Both biochar and compost as single and combined amendments significantly decreased leachable soil $\mathrm{Cu}$ and improved the sunflower shoot yield in a $\mathrm{Cu}$ contaminated soil from a former wood preservation site. Cu concentration in sunflower biomass was also relatively low. It can therefore be suggested that biochar and compost amendments can support sunflower (and potentially other plant) biomass production on Cu-contaminated marginal sites, although site specific testing will be required for each application.

All biochars significantly reduced leachable $\mathrm{Cu}$ and facilitated good plant growth. Of the biochars, BC1 was most effective based on application rate. Results suggest that biomass grown on the site could be used to produce biochars for further site improvement by reducing soil contaminant mobility and facilitating plant growth.

\section{Acknowledgements}

This work was supported by the European Community's Seventh Framework Programme through the grant to the budget of the HOMBRE (www.zerobrownfields.eu) and Greenland (www.greenland-project.eu) projects, Grant Agreement Numbers 265097 and 266124. The authors gratefully acknowledge the inputs and contributions of other members of the HOMBRE Project and Greenland Project consortia. P. Kidd would like to thank the Spanish Ministerio de Economía e Competitividad (CTM2012-39904-C02-01), and FEDER (CTM201039904-C02-01) for additional financial support. M. Mench is grateful to the owner of the wood preservative site.

In addition, we gratefully acknowledge the work and inputs of numerous members of IIAG-CSIC technical staff and students who aided laboratory work (Santiago de Compostela, Spain). 


\section{References}

Aggelides, S. M., \& Londra, P. A. (2000). Effects of compost produced from town wastes and sewage sludge on the physical properties of a loamy and a clay soil. Bioresource Technology, 71(3), 253-259.

Ahmad, M., Rajapaksha, A. U., Lim, J. E., Zhang, M., Bolan, N., Mohan, D. Vithanage, M., Lee, S. S. \& Ok, Y. S. (2014). Biochar as a sorbent for contaminant management in soil and water: a review. Chemosphere, 99, 19-33.

Alburquerque, J. A., Calero, J. M., Barrón, V., Torrent, J., del Campillo, M. C., Gallardo, A., \& Villar, R. (2014). Effects of biochars produced from different feedstocks on soil properties and sunflower growth. Journal of Plant Nutrition and Soil Science, 177(1), 16-25.

Alvarenga, P., Gonçalves, A. P., Fernandes, R. M., De Varennes, A., Vallini, G., Duarte, E., \& Cunha-Queda, A. C. (2009). Organic residues as immobilizing agents in aided phytostabilization: (I) Effects on soil chemical characteristics.

Chemosphere, 74(10), 1292-1300.

Amery, F., Degryse, F., Degeling, W., Smolders, E., \& Merckx, R. (2007). The copper-mobilizing-potential of dissolved organic matter in soils varies 10 -fold depending on soil incubation and extraction procedures. Environmental Science \& Technology, 41(7), 2277-2281.

Amon, T., Amon, B., Kryvoruchko, V., Machmüller, A., Hopfner-Sixt, K., Bodiroza, V., Hrbek, R., Friedel, J., Pötsch, E., Wagentristl, H., Schreiner, M. \& Zollitsch, W. (2007). Methane production through anaerobic digestion of various energy crops grown in sustainable crop rotations. Bioresource Technology, 98(17), 3204-3212.

Antoniadis, V., \& Alloway, B. J. (2002). The role of dissolved organic carbon in the mobility of $\mathrm{Cd}, \mathrm{Ni}$ and $\mathrm{Zn}$ in sewage sludge-amended soils. Environmental Pollution, 117(3), 515-521.

Basso, A. S., Miguez, F. E., Laird, D., Horton, R., Westgate, M. (2013). Assessing the potential of biochar for increasing water-holding capacity of sandy soil. Global Change Biology Bioenergy, 5, 132-143.

Beesley, L., \& Marmiroli, M. (2011). The immobilisation and retention of soluble arsenic, cadmium and zinc by biochar. Environmental Pollution, 159(2), 474-480.

Beesley, L., Moreno-Jiménez, E., \& Gomez-Eyles, J. L. (2010). Effects of biochar and greenwaste compost amendments on mobility, bioavailability and toxicity of inorganic and organic contaminants in a multi-element polluted soil. Environmental Pollution, 158(6), 2282-2287.

Beesley, L., Moreno-Jiménez, E., Gomez-Eyles, J. L., Harris, E., Robinson, B., \& Sizmur, T. (2011). A review of biochars' potential role in the remediation, revegetation and restoration of contaminated soils. Environmental Pollution, 159 (12), 3269-3282. 
Bes, C. \& Mench, M., (2008). Remediation of Cu contaminated topsoils from a wood treatment facility using in situ stabilisation, Environmental Pollution, 156, 1128-1138.

Bes, C., Mench, M., Aulen, M., Gasté, H., \& Taberly J. 2010. Spatial variation of plant communities and shoot $\mathrm{Cu}$ concentrations of plant species at a timber treatment site. Plant Soil, 330, 267-280.

Bolan, N., Kunhikrishnan, A., Thangarajan, R., Kumpiene, J., Park, J., Makino, T., Kirkham, M. B. \& Scheckel, K. (2014). Remediation of heavy metal(loid) contaminated soils-To mobilize or to immobilize? Journal of Hazardous Materials, 266, 141-166.

Bruun, E. W., Petersen, C. T., Hansen, E., Holm, J. K., \& Hauggaard-Nielsen, H. (2014). Biochar amendment to coarse sandy subsoil improves root growth and increases water retention. Soil Use and Management, 30(1), 109-118.

Buss, W., Kammann, C., \& Koyro, H. W. (2012). Biochar Reduces Copper Toxicity in Chenopodium quinoa Willd. in a Sandy Soil. Journal of Environmental Quality, 41(4), 1157-1165.

Cao, X., Ma, L., Liang, Y., Gao, B., \& Harris, W. (2011). Simultaneous immobilization of lead and atrazine in contaminated soils using dairy-manure biochar.

Environmental Science \& Technology, 45(11), 4884-4889.

Chirenje, T., Rivero, C., \& Ma, L. Q. (2002). Leachability of Cu and Ni in wood ashamended soil as impacted by humic and fulvic acid. Geoderma, 108(1), 31-47.

Cornell, R. M., Schwertmann, U. (2003). The Iron Oxides: Structure, Properties, Reactions, Occurrences and Uses, second ed. Wiley VCH, Weinham. DOI: $10.1002 / 3527602097$.

Cundy, A. B., Hopkinson, L., \& Whitby, R. L. (2008). Use of iron-based technologies in contaminated land and groundwater remediation: A review. Science of the Total Environment, 400(1), 42-51.

Cui, L., Li, L., Zhang, A., Pan, G., Bao, D., \& Chang, A. (2011). Biochar amendment greatly reduces rice $C d$ uptake in a contaminated paddy soil: $A$ two-year field experiment. BioResources, 6(3), 2605-2618.

Evanylo, G., Sherony, C., Spargo, J., Starner, D., Brosius, M., \& Haering, K. (2008). Soil and water environmental effects of fertilizer-, manure-, and compost-based fertility practices in an organic vegetable cropping system. Agriculture, Ecosystems \& Environment, 127(1), 50-58.

Fan, J., He, Z., Ma, L. Q., Nogueira, T. A., Wang, Y., Liang, Z., \& Stoffella, P. J. (2012). Calcium water treatment residue reduces copper phytotoxicity in contaminated sandy soils. Journal of Hazardous Materials, 199, 375-382.

Fleming, M., Tai, Y., Zhuang, P., \& McBride, M. (2013). Extractability of Pb and As in historically contaminated orchard soil: Effects of compost amendments, Environmental Pollution, 177, 90-97. 
Gerçel, H. F. (2002). The production and evaluation of bio-oils from the pyrolysis of sunflower-oil cake. Biomass and Bioenergy, 23(4), 307-314.

Giusquiani, P. L., Concezzi, L., Businelli, M., \& Macchioni, A. (1998). Fate of pig sludge liquid fraction in calcareous soil: agricultural and environmental implications. Journal of Environmental Quality, 27(2), 364-371.

Gurwick, N. P., Moore, L. A., Kelly, C., \& Elias, P. (2013). A systematic review of biochar research, with a focus on its stability in situ and its promise as a climate mitigation strategy. PloS one, 8(9), e75932.

Hale, S., Hanley, K., Lehmann, J., Zimmerman, A., \& Cornelissen, G. (2011). Effects of chemical, biological, and physical aging as well as soil addition on the sorption of pyrene to activated carbon and biochar. Environmental Science \& Technology, 45(24), 10445-10453.

Hargreaves, J. C., Adl, M. S., \& Warman, P. R. (2008). A review of the use of composted municipal solid waste in agriculture. Agriculture, Ecosystems \& Environment, 123(1), 1-14.

Haynes, R. J., \& Swift, R. S. (1991). Concentrations of extractable Cu, Zn, Fe and $\mathrm{Mn}$ in a group of soils as influenced by air-and oven-drying and rewetting. Geoderma, 49(3), 319-333.

Herzig, R., Nehnevajova, E., Pfistner, C., Schwitzguebel, J. P., Ricci, A., \& Keller, C. (2014). Feasibility of labile $\mathrm{Zn}$ phytoextraction using enhanced tobacco and sunflower: results of five-and one-year field-scale experiments in Switzerland. International Journal of Phytoremediation, 16(7-8), 735-754.

Houba, V. J. G., Temminghoff, E. J. M., Gaikhorst, G. A., \& Van Vark, W. (2000). Soil analysis procedures using $0.01 \mathrm{M}$ calcium chloride as extraction reagent. Communications in Soil Science \& Plant Analysis, 31(9-10), 1299-1396.

Houben, D., Evrard, L., \& Sonnet, P. (2013). Beneficial effects of biochar application to contaminated soils on the bioavailability of $\mathrm{Cd}, \mathrm{Pb}$ and $\mathrm{Zn}$ and the biomass production of rapeseed (Brassica napus L.). Biomass and Bioenergy, 57, 196-204. Jones, D. L., \& Willett, V. B. (2006). Experimental evaluation of methods to quantify dissolved organic nitrogen (DON) and dissolved organic carbon (DOC) in soil. Soil Biology \& Biochemistry, 38, 991-999.

Karami, N., Clemente, R., Moreno-Jiménez, E., Lepp, N. W., \& Beesley, L. (2011). Efficiency of green waste compost and biochar soil amendments for reducing lead and copper mobility and uptake to ryegrass. Journal of Hazardous Materials, 191(1), 41-48.

Khan, S., Chao, C., Waqas, M., Arp, H. P. H., \& Zhu, Y. G. (2013). Sewage sludge biochar influence upon rice (Oryza sativa $L$ ) yield, metal bioaccumulation and greenhouse gas emissions from acidic paddy soil. Environmental Science \& Technology, 47(15), 8624-8632. 
Kloss, S., Zehetner, F., Buecker, J., Oburger, E., Wenzel, W. W., Enders, A., Lehmann, J. \& Soja, G. (2014). Trace element biogeochemistry in the soil-waterplant system of a temperate agricultural soil amended with different biochars. Environmental Science and Pollution Research, 22, 4513-4526. DOI $10.1007 / \mathrm{s} 11356-014-3685-\mathrm{y}$.

Kolbas A., Mench M., Marchand L., Herzig R., Nehnevajova E. (2014). Phenotypic seedling responses of a metal-tolerant mutant line of sunflower growing on a Cucontaminated soil series. Plant and Soil, 376, 377-397. DOI: 10.1007/s11104-0131974-8.

Komárek, M., Vaněk, A., \& Ettler, V. (2013). Chemical stabilization of metals and arsenic in contaminated soils using oxides-a review. Environmental Pollution, 172, 9-22.

Kong, L. L., Liu, W. T., \& Zhou, Q. X. (2014). Biochar: An Effective Amendment for Remediating Contaminated Soil. Reviews of Environmental Contamination and Toxicology, 228, 83-99.

Kumpiene, J., Lagerkvist, A., \& Maurice, C. (2008). Stabilization of As, Cr, Cu, Pb and $\mathrm{Zn}$ in soil using amendments-a review. Waste management, 28(1), 215-225.

Mallik, A. U., \& Karim, M. N. (2008). Roadside revegetation with native plants: Experimental seeding and transplanting of stem cuttings. Applied Vegetation Science, 11(4), 547-554.

Megharaj, M., Ramakrishnan, B., Venkateswarlu, K., Sethunathan, N., \& Naidu, R. (2011). Bioremediation approaches for organic pollutants: A critical perspective. Environmental International, 37, 1362-1375.

Mench, M., \& Bes, C. (2009). Assessment of the ecotoxicity of topsoils from a wood treatment site. Pedosphere, 19, 143-155.

Mench, M., Lepp, N., Bert, V., Schwitzguébel, J. P., Gawronski, S. W., Schröder, P., \& Vangronsveld, J. (2010). Successes and limitations of phytotechnologies at field scale: outcomes, assessment and outlook from COST Action 859. Journal of Soils and Sediments, 10(6), 1039-1070.

Merckx, R., Brans, K., \& Smolders, E. (2001). Decomposition of dissolved organic carbon after soil drying and rewetting as an indicator of metal toxicity in soils. Soil Biology and Biochemistry, 33(2), 235-240.

Namgay, T., Singh, B., \& Singh, B. P. (2010). Influence of biochar application to soil on the availability of $\mathrm{As}, \mathrm{Cd}, \mathrm{Cu}, \mathrm{Pb}$, and $\mathrm{Zn}$ to maize (Zea mays L.). Soil

Research, 48(7), 638-647.

Nehnevajova, E., Herzig, R., Bourigault, C., Bangerter, S \& Schwitzguébel, J-P. (2009). Stability of enhanced yield and metal uptake by sunflower mutants for improved phytoremediation. International Journal of Phytoremediation, 11 (4), 329346. 
Nehnevajova E, Herzig R, Erismann KH, Schwitzguebel J-P. (2007). Chemical mutagenesis - an efficient technique to enhance metal accumulation and extraction in sunflowers. International Journal of Phytoremediation, 9, 149-165.

Nixon, D. J., Stephens, W., Tyrrel, S. F., \& Brierley, E. D. R. (2001). The potential for short rotation energy forestry on restored landfill caps. Bioresource Technology, 77(3), 237-245.

Ohsowski, B.M., Klironomos, J.N., Dunfield, K.E., \& Hart, M.M. (2012). Potential of soil amendments for restoring severely disturbed grasslands. Applied Soil Ecology. $60,77-83$.

Park, J. H., Choppala, G. K., Bolan, N. S., Chung, J. W., \& Chuasavathi, T. (2011). Biochar reduces the bioavailability and phytotoxicity of heavy metals. Plant and Soil, 348(1-2), 439-451.

Redman, A. D., Macalady, D. L., \& Ahmann, D. (2002). Natural organic matter affects arsenic speciation and sorption onto hematite. Environmental Science \& Technology, 36(13), 2889-2896.

Römkens, P. F. A. M., Bouwman, L. A., \& Boon, G. T. (1999). Effect of plant growth on copper solubility and speciation in soil solution samples. Environmental Pollution, 106(3), 315-321.

Ruttens, A., Mench, M., Colpaert, J. V., Boisson, J., Carleer, R., \& Vangronsveld, J. (2006). Phytostabilization of a metal contaminated sandy soil. I: Influence of compost and/or inorganic metal immobilizing soil amendments on phytotoxicity and plant availability of metals. Environmental Pollution, 144(2), 524-532.

Sizmur, T., Wingate, J., Hutchings, T., \& Hodson, M. E. (2011). Lumbricus terrestris L. does not impact on the remediation efficiency of compost and biochar amendments. Pedobiologia, 54, S211-S216.

Tong, X. J., Li, J. Y., Yuan, J. H., \& Xu, R. K. (2011). Adsorption of Cu (II) by biochars generated from three crop straws. Chemical Engineering Journal, 172(2), 828-834.

Uchimiya, M., Chang, S., \& Klasson, K. T. (2011). Screening biochars for heavy metal retention in soil: role of oxygen functional groups. Journal of Hazardous Materials, 190(1), 432-441.

Venegas, A., Rigol, A., \& Vidal, M. (2015). Viability of organic wastes and biochars as amendments for the remediation of heavy metal-contaminated soils. Chemosphere, 119, 190-198.

Weng, L., Temminghoff, E. J., Lofts, S., Tipping, E., \& Van Riemsdijk, W. H. (2002). Complexation with dissolved organic matter and solubility control of heavy metals in a sandy soil. Environmental Science \& Technology, 36(22), 4804-4810.

Wenzel, W. W., \& Blum, W. E. H. (1999). Effect of sampling, sample preparation and extraction techniques on mobile metal fractions in soils. In: Adriano, D. C., Chen, Z.- 
S., Yang, S.-S., Iskandar, I.K. (eds.). Biogeochemistry of Trace Metals. Advances in Environmental Sciences, Northwood, UK: Science Reviews, 121-172.

Zhao, X., Monnell, J. D., Niblick, B., Rovensky, C. D., Landis, A. E. (2014). The viability of biofuel production on urban marginal land: An analysis of metal contaminants and energy balance for Pittsburgh's Sunflower Gardens, Landscape and Urban Planning, 124, 22-33. 